OPEN ACCESS

Edited by: Andrea Genre,

University of Turin, Italy

Reviewed by:

Alessandra Salvioli,

University of Turin, Italy

Maria J. Pozo,

Consejo Superior de Investigaciones

Científicas, Spain

*Correspondence:

Louis Mercy

mercy@inoq.de

${ }^{\dagger}$ Present address:

Amaia Nogales,

Linking Landscape, Environment,

Agriculture and Food - Instituto

Superior de Agronomia, University

of Lisbon, Lisbon, Portugal

¥These authors have contributed equally to this work.

Specialty section:

This article was submitted to Plant Microbe Interactions,

a section of the journal

Frontiers in Plant Science

Received: 08 November 2016 Accepted: 10 March 2017 Published: 30 March 2017

Citation:

Mercy L, Lucic-Mercy E, Nogales A,

Poghosyan A, Schneider $C$ and Arnholdt-Schmitt B (2017)

A Functional Approach towards Understanding the Role of the Mitochondrial Respiratory Chain in an Endomycorrhizal Symbiosis.

Front. Plant Sci. 8:417. doi: 10.3389/fpls.2017.00417

\section{A Functional Approach towards Understanding the Role of the Mitochondrial Respiratory Chain in an Endomycorrhizal Symbiosis}

\author{
Louis Mercy ${ }^{1 \ddagger}$, Eva Lucic-Mercy ${ }^{1 \ddagger}$, Amaia Nogales ${ }^{2 t}$, Areg Poghosyan ${ }^{1}$, \\ Carolin Schneider ${ }^{1}$ and Birgit Arnholdt-Schmitt ${ }^{3,4,5}$
}

${ }^{1}$ INOQ GmbH, Schnega, Germany, ${ }^{2}$ ICAAM, University of Évora, Évora, Portugal, ${ }^{3}$ Functional Cell Reprogramming and Organism Plasticity (FunCrop), EU Marie Curie Chair, ICAAM, University of Évora, Évora, Portugal, ${ }^{4}$ Functional Genomics and Bioinformatics, Department of Biochemistry and Molecular Biology, Federal University of Ceará, Fortaleza, Brazil,

${ }^{5}$ Science and Technology Park Alentejo (PCTA), Évora, Portugal

Arbuscular mycorrhizal fungi (AMF) are crucial components of fertile soils, able to provide several ecosystem services for crop production. Current economic, social and legislative contexts should drive the so-called "second green revolution" by better exploiting these beneficial microorganisms. Many challenges still need to be overcome to better understand the mycorrhizal symbiosis, among which (i) the biotrophic nature of AMF, constraining their production, while (ii) phosphate acts as a limiting factor for the optimal mycorrhizal inoculum application and effectiveness. Organism fitness and adaptation to the changing environment can be driven by the modulation of mitochondrial respiratory chain, strongly connected to the phosphorus processing. Nevertheless, the role of the respiratory function in mycorrhiza remains largely unexplored. We hypothesized that the two mitochondrial respiratory chain components, alternative oxidase (AOX) and cytochrome oxidase (COX), are involved in specific mycorrhizal behavior. For this, a complex approach was developed. At the pre-symbiotic phase (axenic conditions), we studied phenotypic responses of Rhizoglomus irregulare spores with two AOX and COX inhibitors [respectively, salicylhydroxamic acid (SHAM) and potassium cyanide $(\mathrm{KCN})$ ] and two growth regulators (abscisic acid - ABA and gibberellic acid - Ga3). At the symbiotic phase, we analyzed phenotypic and transcriptomic (genes involved in respiration, transport, and fermentation) responses in Solanum tuberosum/Rhizoglomus irregulare biosystem (glasshouse conditions): we monitored the effects driven by ABA, and explored the modulations induced by SHAM and KCN under five phosphorus concentrations. $\mathrm{KCN}$ and SHAM inhibited in vitro spore germination while ABA and Ga3 induced differential spore germination and hyphal patterns. ABA promoted mycorrhizal colonization, strong arbuscule intensity and positive mycorrhizal growth dependency (MGD). In ABA treated plants, $R$. irregulare induced down-regulation of StAOX gene isoforms and up-regulation of genes involved in plant COX pathway. In all phosphorus $(\mathrm{P})$ concentrations, blocking AOX or COX induced opposite mycorrhizal patterns in planta: KCN induced higher Arum-type arbuscule density, positive MGD but lower root colonization compared to SHAM, which favored Paris-type formation and 
negative MGD. Following our results and current state-of-the-art knowledge, we discuss metabolic functions linked to respiration that may occur within mycorrhizal behavior. We highlight potential connections between AOX pathways and fermentation, and we propose new research and mycorrhizal application perspectives.

Keywords: AMF, AOX, COX, phosphorus, mycorrhizal growth dependency, mycorrhizal type, Rhizoglomus irregulare, Solanum tuberosum

\section{INTRODUCTION}

The political, social and economic context should, in the next years, favor the exploration and exploitation of beneficial soil organisms for crop production. Government policy initiatives (European Directive 2009/128/EC) and consumer demand will lead to alternative production methods in order to reduce the use of phytosanitary products and fertilizer inputs. Thus, agroecological strategies are increasingly explored and recall some basic definitions that (re)integrate the plant in its environment. The soil is the first habitat for plants which continues to interact at all stages of plant's life cycles (Jeffries et al., 2003). The soil is also one of the main reservoirs of ecosystem services found on Earth, provided by a wide range of microorganisms, including bacteria and some soil fungi, such as arbuscular mycorrhizal fungi (AMF; Gianinazzi et al., 2010). The predominant mutualistic symbiotic relationship between AMF and plant roots was established over 400 million years ago (Brundrett, 2002) in more than 200,000 species, which belong to $74 \%$ of plant families (van der Heijden et al., 2015). AMF are obligate biotrophs, represented by at least 289 species $^{1}$ found worldwide under a wide range of ecological conditions. Many positive mycorrhizal effects on host plants have been reported. AMF can (i) improve plant growth by a better transfer of water and inorganic nutrients, especially phosphorus (Smith and Read, 2008); (ii) increase plant-pathogen resistance and plant health (Whipps, 2004; Pozo et al., 2009); (iii) boost plant photosynthesis (Quarles, 1999); (iv) stabilize soil by the excretion of the fungal glycoprotein, glomalin (Rillig and Steinberg, 2002; Bedini et al., 2009); (v) alleviate the impact of abiotic stresses such as cold or heat (Volkmar and Woodbury, 1989; Charest et al., 1993; Zhu et al., 2010, 2011), salinity (Porras-Soriano et al., 2009), drought (Aroca et al., 2007), nutritive starvation (Smith and Read, 2008) or heavy metals (Karimi et al., 2011). In return, it is believed that

\footnotetext{
Abbreviations: ABA, abscisic acid; AM-inducible transporter, arbuscular mycorrhizal inducible transporter; AMF, arbuscular mycorrhizal fungi; AMT, ammonium transporter; AOX, alternative oxidase; COX, cytochrome oxidase; DAI, day after inoculation; DPU, direct phosphate uptake; FW, fresh weight; Ga3, gibberellic acid; HA, H+-ATPase; INT, iodonitrotetrazolium salt; KCN, potassium cyanide; $\mathrm{LDH}$, lactate dehydrogenase; $\mathrm{M}$, mycorrhizal plant; MGD, mycorrhizal growth dependency; MPT, mitochondrial phosphate transporter; MPU, mycorrhizal phosphate uptake; NM, non-mycorrhizal plant; P, phosphorus; PDC, pyruvate decarboxylase; ppm, part per million; PT, phosphate transporter; SHAM, salicylhydroxamic acid; WAI, week after inoculation; Mycorrhizal parameters: F\%, frequency of mycorrhiza; M\%, intensity of mycorrhiza in whole root system; $\mathrm{m} \%$, intensity of mycorrhiza in mycorrhizal root fragment; $\mathrm{A} \%$, intensity of arbuscules in whole root system; a\%, intensity of arbuscules in mycorrhizal root fragment; V\%, intensity of vesicles in whole root system; v\%, intensity of vesicles in mycorrhizal root fragment; $\mathrm{H} \%$, intensity of hyphae in whole root system; h\%, intensity of hyphae in mycorrhizal root fragment.

${ }^{1}$ http://glomeromycota.wixsite.com/lbmicorrizas/cpia
}

AMF benefit from the plant's carbohydrates supply (Bago et al., 2003) associated with the stimulation of fatty acid synthesis in fungal hyphae (Trépanier et al., 2005).

Arbuscular mycorrhizal fungi are probably one of the essential components of the "second green revolution" (Lynch, 2007), but their implementation faces some major difficulties, namely restrictions from plant producer's perspective, product costs, producer awareness level and variability in mycorrhizal inoculum quality (Vosátka et al., 2008; Ijdo et al., 2011; Berruti et al., 2016). But there are also limitations inherent to the biological system itself since mycorrhizal benefits are not always guaranteed (Vosátka et al., 2008; Ijdo et al., 2011; Malusá et al., 2012) and the physicochemical properties of targeted soils can negatively impact the symbiosis (Smith and Smith, 2011a,b). One of the biggest challenges of mycorrhizal inoculum field application is the high phosphorus (P) content often encountered under conventional cropping, due to $\mathrm{P}$ fertilizer input. It is known that high phosphorus concentrations (or its inorganic salt phosphate) systematically inhibit mycorrhizal colonization (Smith and Read, 2008; Breuillin et al., 2010), and the physiological signaling generated by this element appears systemic since foliar application can lead to the same effects (Sanders, 1975; Schreiner and Linderman, 2005; Schreiner, 2010).

Phosphate affects not only the establishment but also the functioning of mycorrhizal symbiosis. Fungal structure development of the internal mycelium can be divided in two general anatomical groups described by Gallaud (1905). The Arum-type consists of characteristic highly branched arbuscules within cortical cells, formed from a short side hyphal branch. The Paris-type is characterized by the development of extensive intracellular coiled hyphae, which spreads from cell to cell sometimes with only low rates of arbuscule-like branch formation. McArthur and Knowles (1992) have shown in potato root that AMF develop preferentially Arum-type under low $\mathrm{P}$ while Paris-type occurs under high P. These two mycorrhizal types may act in different ways within plant roots. In rice, the symbiotic phosphate transporter (PT) OsPt11 is preferentially active in arbuscule branches but not around coiled hyphae (Kobae and Hata, 2010). Given that increasing phosphorus concentration is often associated with a decrease of mycorrhizal growth response (MGD; Smith and Smith, 2011a), these data suggest differential plant fitness related to the mycorrhizal type they harbor. Despite numerous studies, there is not yet a complete explanation for the P inhibition. Therefore, there is an urgent need to better understand the physiological bases of this phenomenon in order to define innovative strategies to improve mycorrhizal development and performance, which are sine qua non conditions to realize 
the mycorrhizal implementation under high $\mathrm{P}$ crop field conditions.

One obvious connection between $\mathrm{P}$ and organism behavior is the mitochondrial respiration activity, in which P plays a crucial role as energetic component of ATP. In most plants and fungi, the respiration yield is modulated by the electron partitioning flow shared between the cytochrome oxidase (COX) and the alternative oxidase (AOX) pathways that take part in the electron transport chain (Vanlerberghe, 2013). Both transfer electrons to $\mathrm{O}_{2}$ (which results in water formation), but it is usually assumed that AOX is a non-conserving energy pathway because it does not contribute to ATP formation (Vanlerberghe, 2013) and is regulated by the mitochondrial redox status and the glycolytic flux.

In plants, the COX pathway involves cytochrome $c$ reductase, cytochrome $c$ and cytochrome $c$ oxidase enzymes. Whereas cytochrome $c$ (Cytc) is composed of a single small polypeptide, cytochrome $c$ oxidase is a multimeric complex composed of several different subunits, encoded by the mitochondrial and the nuclear genome (Welchen et al., 2002). Subunit Vb (COXVb) is the most conserved among nuclear-encoded subunits (Rizzuto et al., 1991). Cytc is essential for plant growth and survival and the knock-out of both Cytc genes in Arabidopsis is lethal to the plants while they participate for complex IV stability (Welchen et al., 2012). AOX plays an important role during various stress responses (such as P limitation, Sieger et al., 2005; Plaxton and Tran, 2011) and in specific developmental phases, depending on the expressed isoform (Umbach et al., 2006; Zsigmond et al., 2008; Vanlerberghe, 2013). However, its metabolic significance is much less clear but specific metabolic functions must be involved when the AOX pathway is engaged to sustain basal general metabolic processes associated with the a specific redox status $\left(\mathrm{NAD}(\mathrm{P})^{+} / \mathrm{NAD}(\mathrm{P}) \mathrm{H}\right)$ cell pool in order to cope with energy demand. In this regard, fermentation metabolism activity could play an important role (Sakano, 2001). The best-known function of fermentative metabolism is to recycle $\mathrm{NADH}$ to $\mathrm{NAD}^{+}$to avoid the depletion of the cytosolic $\mathrm{NAD}^{+}$pool and inhibition of glycolysis when oxidative phosphorylation is impaired (Sakano, 2001). However, no data is available about the importance of these processes in mycorrhizal symbiosis.

In fungi, AOX plays a role in growth regulation and development, resistance, pathogenesis and pathogenicity, and may contribute to fungal ecological fitness (Umbach and Siedow, 2000; Uribe and Khachatourians, 2008; Ruiz et al., 2011; Grahl et al., 2012; Thomazella et al., 2012; Xu T. et al., 2012). Unlike plants, in which AOX form small multigenic families, the analysis of the fungal genomes currently available reveals that a majority of fungal species possessing the AOX pathway have only one gene sequence, with a maximum of three sequences per genome (Mercy et al., 2015).

In particular, very few studies were conducted to elucidate the role of the two electron pathways in AMF, despite their known importance for the growth of many organisms:

- It was shown that the COX1 protein content is increased in hyphae (Besserer et al., 2006) while the transcript level of COXIV is increased in hyphae as compared to spores (Besserer et al., 2008) within days succeeding application of strigolactone analogous (GR24) in Gigaspora rosea. Hyphal development seems, therefore, associated with the COX pathway, and it corresponds to a higher $\mathrm{NAD}(\mathrm{P}) \mathrm{H}$ protein activity (concomitant with an increase in NADH dehydrogenase activity) and ATP production observed at hyphal tip (Besserer et al., 2008).

- Existence of the cyanide-insensitive respiration pathway in AMF was highlighted by the presence of an $A O X$ sequence in Rhizoglomus irregulare genome, close to the Mucoromycotina AOX 1 (Campos et al., 2015; Mercy et al., 2015), but limited functional data were published. By using SHAM as AOX pathway inhibitor, Besserer et al. (2009) suggested a role of AOX during Gigaspora rosea spore germination. Mitochondrial changes (density and respiration) were observed in response to branching factors (Tamasloukht et al., 2003; Besserer et al., 2006), which may suggest a role of the AOX or COX pathways during the pre-symbiotic phase. Campos et al. (2015) observed a coincident of up-regulation of the tomato $A O X 1$ genes and down-regulation of the RiAOX gene during the first six weeks of symbiosis establishment. Expression data obtained under coldstress conditions showed that the presence of AMF is able to induce an opposite plant mitochondrial respiratory pattern, by potentially reversing the electron route pathway from the AOX to the COX (Liu et al., 2015). Note that the growth regulator abscisic acid (ABA) was shown to play a crucial role in arbuscule formation and functionality (Herrera-Medina et al., 2007; Martin-Rodriguez et al., 2010, 2011; Aroca et al., 2013), while it regulates the AOX gene expression and activity in plants (Finkelstein et al., 1998; Choi et al., 2000; Rook et al., 2006; Giraud et al., 2009; Lynch et al., 2012; Wind et al., 2012). Nevertheless, no roles were clearly defined for the respiratory pathways during spore dormancy or the symbiotic phase.

Although several studies suggest a connection between respiration and $\mathrm{P}$ nutrition, little is known about the uptake and transport of $\mathrm{P}$ in connection with the respiratory pathways involved. Plant Pi uptake across the plasma membrane is mediated by $\mathrm{Pi} / \mathrm{H}^{+}$symporters belonging to the $\mathrm{Pht} 1$ gene family (Bucher, 2007). In mycorrhizal plants, two P uptake pathways were identified: the "direct phosphate uptake" pathway (DPU), mediated by high affinity transporters that are strongly expressed in roots (Smith et al., 2011) and the "mycorrhizal phosphate uptake" pathway (MPU), relying on AM-inducible Pi transporters, crucial for Pi flux across the periarbuscular membrane at the mycorrhizal interface (Javot et al., 2007; Yang et al., 2012). Inorganic phosphate transporters are also present on the inner mitochondrial membrane and are represented by two families: the phosphate/dicarboxylate carrier (DIC) and the phosphate carrier Pht3 (here named 'MPT' for mitochondrial phosphate transporter). MPTs deliver most of the Pi required by the mitochondrial ATP synthase complex (Kiiskinen et al., 1997).

This work is an exploration of the functional framework of the cyanide-sensitive and cyanide-insensitive respiration pathways in the mycorrhizal system Solanum tuberosum/Rhizoglomus irregulare (whose genomes are available). To study this complex aspect in a holobiont system, three strategies were developed: the first assay was implemented to study the impact of respiratory inhibitors SHAM (AOX inhibitor) and KCN (COX inhibitor), 
as well as, two antagonistic phytohormones (ABA and Ga3) on mycorrhizal spore behavior at the pre-symbiotic phase (axenic condition). The second trial was designed to analyze transcript variations of several genes involved in respiration and fermentation pathways using $\mathrm{ABA}$, a phytohormone known to promote the mycorrhizal symbiosis and also known to be one regulator of the AOX pathway. Then, a third assay consisted to set a non-lethal pharmacological approach using KCN and SHAM treatments, under five different phosphorus concentrations. Our data reveal differential mechanisms that shape plant and fungal behavior by affecting yield, plant FW, mycorrhizal type, hyphal development and MGD. We show that the electron flow partitioning is a key determinant in mycorrhizal behavior and mycorrhizal effects, at least in the $S$. tuberosum/R. irregulare biosystem. We discuss its potential relevance in regard to specific metabolic pathways, notably to fermentation, but also for the mycorrhizal application.

\section{MATERIALS AND METHODS}

\section{Experiment 1: Spore In vitro Assay}

Four viable and mature in vitro spores of $R$. irregulare were deposited on four cardinal directions in Petri dishes filled with water $+3.5 \%$ Gelrite $^{\mathrm{TM}}$ (Duchefa Biochemie, The Netherlands), containing or not ABA (1 mM), Ga3 (1 mM), SHAM (1 or $5 \mathrm{mM}$ ) or $\mathrm{KCN}$ (1 or $5 \mathrm{mM})$. Six plates were tested for each treatment and incubated in dark at $28^{\circ} \mathrm{C}$ in upside down position. At 24 days after inoculation (DAI), hyphal germination patterns were observed and the germination rate was calculated. Spore viability was also assessed by iodonitrotetrazolium salt (INT) and spores, which appeared red due to the presence of formazan, were counted. INT is a marker of mitochondrial activity (Walley and Germida, 1995; Mukerji et al., 2002). It is known that INT reduction (the conversion of INT to formazan by two electrons and two protons) is connected to the electron chain transport (Berridge et al., 2005) but the exact process within cell is not yet clearly identified.

\section{Experiment 2: Effect of ABA-Driven Pre-trial on Mycorrhizal Performance, Respiration, and Fermentation-Related Genes}

The aim of this experiment was to study in a small experimental set the variation of some genes involved in the mitochondrial electron chain and fermentation associated with mycorrhizal performances. In vitro S. tuberosum plantlets (cv K19-99-0012) were grown in growth chambers $\left[20^{\circ} \mathrm{C} / 17^{\circ} \mathrm{C}\right.$ (day/night), $16 \mathrm{~h}$ $\mathrm{d}^{-1}$ photoperiod, $70 \%$ relative humidity and $55 \mu \mathrm{mol} \mathrm{m}{ }^{-2} \mathrm{~s}^{-1}$ photon flux density] on MS medium (Murashige and Skoog, 1962), supplemented with $20 \mathrm{~g} \cdot \mathrm{l}^{-1}$ sucrose, $3.5 \mathrm{~g} \mathrm{l}^{-1}$ Gelrite ${ }^{\mathrm{TM}}$ (Duchefa Biochemie, The Netherlands) adjusted to $\mathrm{pH} 5.6$ before autoclaving $\left(121^{\circ} \mathrm{C}\right.$ for $\left.15 \mathrm{~min}\right)$. Plantlets were pre-treated or not with $\mathrm{ABA}$, a known promoter of the AOX pathway, added in culture medium to $0.1 \mathrm{mM}$ final concentration.
Ten-day-old in vitro plantlets were transplanted in $1 \mathrm{~L}$ pots containing $100 \%$ sterilized sand (baked twice in a dry oven, at $120^{\circ} \mathrm{C}$ for $\left.6 \mathrm{~h}\right)$. Plants were inoculated (M) or not (NM) at transplanting time with 100 in vitro spores of $R$. irregulare INOQ strain QS69 placed at the vicinity of the root and grown in a glasshouse [Loitze, Germany; $32^{\circ} \mathrm{C} / 25^{\circ} \mathrm{C}$ (day/night), natural light and day (July-August)]. In this way, no direct contact between AMF and ABA treatment could occur. Plants were fertilized once a week with $50 \mathrm{ml}$ of a modified Hoagland's solution without $\mathrm{P}$ ( $1 \mathrm{ppm} \mathrm{P}$ was mixed in the sand during pot preparation). The watering was performed when needed with the same volume for all plants. Precautions were taken to avoid watering the shoots. Potato plant and soil harvesting were conducted at 8 weeks after inoculation (WAI). Plant growth parameters such as the shoot, root, and tuber FW were measured. The evaluation of mycorrhizal development was performed according to Trouvelot et al. (1986) method after root staining with China Ink (Vierheilig et al., 1998). The MGD was calculated for several potato parameters (root, shoot, yield and total biomass FW) according to the following formula (Plenchette et al., 1983): $\left[100^{*}((M-N M) / M)\right]$, expressed as percentage.

\section{Experiment 3: Effect of Different Phosphorus Concentrations and Respiratory Inhibitors on Mycorrhizal Performance}

A multifactorial experiment was designed to test the effects of different $\mathrm{P}$ concentrations and respiratory chain inhibitors on mycorrhizal and plant parameters. Mycorrhizal inoculum was produced in bed cultures with a mix of three plant species (Trifolium pratense, Zea mays, and S. tuberosum) in sterile sand, containing 92,000 propagules/l [determined by the Most Probable Number of mycorrhizal propagules (MPN) test, Gianinazzi-Pearson et al., 1985]. In vitro potato plantlets were grown in growth chambers as described in the Experiment 2 before being transplanted to a glasshouse [Loitze, Germany; $32^{\circ} \mathrm{C} / 25^{\circ} \mathrm{C}$ (day/night), natural light and day (July-August)] and grown for 8 weeks in $1 \mathrm{~L}$ pots containing $100 \%$ sterilized sand (baked twice in a dry oven, at $120^{\circ} \mathrm{C}$ for $6 \mathrm{~h}$ ). Plants were inoculated or not with $R$. irregulare (INOQ strain QS69) at transplanting time, by mixing $4 \%$ of a mycorrhizal inoculum containing spores and mycorrhizal root fragments in the growth substrate.

Five P concentrations were tested: 1, 10, 50, 100, and 300 ppm $\mathrm{P}$ (respectively, $0.032,0.323,1.614,3.228$, and $9.687 \mathrm{mM}$ as final concentration), corresponding to the concentrations of practical reality in crop field soils (50, 100, and $300 \mathrm{ppm}$ ) and in mycorrhizal production under glasshouse conditions ( 1 and $10 \mathrm{ppm}$ ). To achieve those concentrations, $\mathrm{KH}_{2} \mathrm{PO}_{4}$ was mixed directly into growth substrate. To test the contribution of each respiratory pathway in mycorrhizal and non-mycorrhizal plants at each $\mathrm{P}$ concentration, two respiratory chain inhibitors were used: KCN and SHAM (0.1 mM), which inhibit COX and AOX, respectively. The inhibitors were dissolved in sterile water and added to substrate at 08:00 a.m. in one application 7 DAI, which corresponds to the end of the acclimatization period. 
The experimental design for the inhibitor studies included (1) non-treated plants, non-inoculated (NM) and inoculated plants (M); (2) KCN treated plants that were non-inoculated (KCN) or inoculated (M KCN) plants; (3) SHAM treated plants that were non-inoculated (SHAM) or inoculated (M SHAM) plants. Plants were fertilized once a week with $50 \mathrm{ml}$ of a modified Hoagland's solution without $\mathrm{P}$, and were watered as needed with the same volume for all plants. Precautions were taken to avoid watering and treating the shoots.

Potato plant and soil harvesting were conducted at 8 WAI. Plant growth parameters including the shoot, root, and tuber FW, were measured. The evaluation of mycorrhizal development was performed according to the Trouvelot et al. (1986) method after root staining with China Ink (Vierheilig et al., 1998). Parameters investigated (by observing with a microscope 30 root fragments slide per sample) included frequency of mycorrhiza (F \%), intensity of mycorrhiza, arbuscule, vesicle and intraradical hyphal colonization in whole root system (respectively, $\mathrm{M} \%, \mathrm{~A} \%, \mathrm{~V} \%$, and $\mathrm{H} \%$ ) and within mycorrhizal root fragments (respectively, $\mathrm{m} \%$, a $\%, \mathrm{v} \%$, and $\mathrm{h} \%)$. The spore production was evaluated in $\mathrm{M}$ plants for each repetition by isolating and counting spores after performing the wet sieving method (Gerdemann and Nicolson, 1963) using $3 \times 10 \mathrm{~g}$ of dried substrate. The MGD was calculated for several potato parameters (root, shoot, yield, and total biomass FW) according to the following formula (Plenchette et al., 1983): [100* $((M-N M) / M)]$, expressed as percentage. The $\% \mathrm{FW}$ of root, shoot or tuber was calculated as follows: [Plant organ (root, shoot part or tuber FW)/Total FW] $\times 100$.

\section{Bioinformatic Analyses}

Transcript accumulation analyses of plant and fungal genes involved in respiration, nutrient transport and fermentation were performed. Genes of interest are listed in Supplementary Table S1. To obtain the sequences of some targeted genes, a database search was performed using the $R$. irregulare and S. tuberosum genomes databases ${ }^{2,3}$ and the INRA Glomus database $\mathrm{e}^{4}$. Full-length amino acid sequences of $R$. irregulare, S. tuberosum and those from fungi and plants were acquired from the JGI database ${ }^{5}$ and GenBank $^{6}$ and were aligned by CLUSTALW and imported into the Molecular Evolutionary Genetics Analysis (MEGA) package version 6 (Tamura et al., 2013). Phylogenetic analyses were conducted using the neighborjoining (NJ) method implemented in MEGA with the pairwise deletion option for handling alignment gaps and with the Poisson correction model for distance computation. Bootstrap tests were conducted using 1000 replicates.

\section{Quantitative RT-PCR}

For both glasshouse trials, $100 \mathrm{mg}$ of root samples were stored in RNAlater (Qiagen) solution at the time of harvest. Total RNA was extracted from $100 \mathrm{mg}$ of roots conserved in RNAlater (Qiagen)

\footnotetext{
${ }^{2}$ http://genome.jgi.doe.gov/Gloin1/Gloin1.home.html

${ }^{3}$ http://potato.plantbiology.msu.edu/integrated_searches.shtml

${ }^{4}$ http://mycor.nancy.inra.fr/IMGC/GlomusGenome/index3.html

${ }^{5}$ http://genome.jgi.doe.gov/

${ }^{6}$ http://www.ncbi.nlm.nih.gov/genbank/
}

using the RNeasy Plant Mini kit (Qiagen). cDNA synthesis was performed with an oligo(dT) primer (Promega) and reverse transcriptase (Masterscript ${ }^{\mathrm{TM}}$ Kit, 5 Prime, Germany) using $250 \mathrm{ng}$ of total RNA. The cDNAs were 1:10 diluted and amplified using the 7500/7500 Fast Real-Time PCR System (Applied Biosystems ${ }^{\circledR}$, USA). Amplification reactions were prepared using a SYBR Green PCR Master kit (Maxima) SYBR Green/ROX qPCR Master Mix (Thermo Scientific) using the following concentrations: $6 \mu \mathrm{l}$ of PCR water, $9 \mu \mathrm{L}$ of $2 \mathrm{x}$ Maxima SYBR Green/ROX qPCR Master Mix (Thermo Scientific) $0.5 \mu \mathrm{L}$ of each forward and reverse primer $(10 \mathrm{mM})$ and $2 \mu \mathrm{l}$ of the cDNA template. Three independent biological replicates were analyzed per treatment and each sample was analyzed in duplicate. The specificity of the different amplicons was checked by a melting curve analysis at the end of the amplification protocol. Several candidates were evaluated for further use as reference gene for normalization of the transcript data of target genes, comprising a set of housekeeping genes, rRNA genes and other sequences (data not shown). After evaluation of expression stability using the applications BestKeeper` and NormFinder (Andersen et al., 2004; Pfaffl et al., 2004), two genes for potato (StEF1 $\alpha$ and StUbc, Gallou, 2011, Supplementary Table S1) and one genes for R. irregulare (GiICL, Lammers et al., 2001, Supplementary Table S1) were chosen as reference genes for our experimental conditions. Expression of target genes was evaluated by efficiency corrected relative quantification for $R$. irregulare genes and using the geometric normalization factors for potato where two genes are used for normalization (Pfaffl, 2001; Vandesompele et al., 2002). Standard curves of a fourfold dilution series from pooled cDNAs were used for PCR efficiency calculations. All primers used are listed in Supplementary Table S1.

\section{Statistical Analyses}

In the Experiment 1-3, differences in plant and fungal growth parameters and gene expression between treatments were examined by a one-way analysis of variance (ANOVA), after log or arcsin transformation of values as indicated in figure legends. Dunnett's test was conducted to identify significant differences ( $P<0.05$, symbolized by stars $)$ compared to a specified standard control and Duncan's multiple range tests were performed to identify significant differences $(P<0.05$, symbolized by letters $)$ among $\mathrm{P}$ concentrations (after standardization against specified control). Data analysis was performed with the SAS enterprise guide 4.1 (SAS Institute Inc., Cary, NC, USA).

In the Experiment 3, the relationships between $\mathrm{P}$ concentration and plant or fungal parameters were investigated by least squares stepwise multiple linear regression with replication using experiment-wise type I error rates of 0.05 for coefficients calculated using the Dunn-Šidák method (Ury, 1976). For each fungal parameter, the complete candidate model included up to the third degree of $\mathrm{P}$ concentration or of $\ln \mathrm{P}$, three qualitative variables binary coded as 0 or 1 for control, $\mathrm{KCN}$, SHAM plus all first and second level interactions between powers of $\mathrm{P}$ and qualitative variables. Whenever considered necessary after graphical exploration of the data, modeling was done with fungal variables or $\mathrm{P}$ concentration logarithmically, arcsin transformed or not with the major criteria for model selection 
being the coefficient of determination (data not shown). Lack of fit was tested for $P=0.05$ and coefficients of determination $\left(R^{2}\right)$ are presented as proportion of the maximum $R^{2}$ possible (Draper and Smith, 1998). Linear regressions and analyses of variances were done with Statgraphics 4.2 (STSC, Inc., Rockville, MD, USA), all other statistics used in regression were performed in Excel $^{\circledR}$ (Microsoft Corporation). Least squares stepwise multiple linear regression data are given in Supplementary Table S2 (under each fungal parameter) and Supplementary Table S3 (under each plant parameter).

\section{RESULTS}

\section{Experiment 1 - Influences of Respiratory Inhibitors and Two Antagonistic Plant Growth Regulators at the Pre-symbiotic Phase}

Compared to non-treated spores, ABA treatment decreased the germination rate (Figure 1A) but increased significantly the viable spore fraction (containing formazan crystals, Figure 1B). Ga3 treatment induced an opposite effect (Figures 1A,B). Both SHAM and KCN, at 1 and $5 \mathrm{mM}$, inhibited spore germination (Figure 1A), but induced an opposite reaction on INT reduction ability (Figure 1B): red stained spores rate was higher in $\mathrm{KCN}$ (for both concentrations) than in SHAM at 1 and $5 \mathrm{mM}$, and also than in non-treated spores (with $5 \mathrm{mM} \mathrm{KCN}$ ). Then, ABA induced a significant hyphal branching pattern around the germinated spores (Figures 1C,E) compared to spores treated or not with Ga3 (Figures 1C,D).

\section{Gene Sets for Transcriptomic Study in Experiments 2 and 3}

The bioinformatic analyses conducted in this study revealed that the $A O X$ family of $S$. tuberosum is composed of three $A O X 1$ and one $A O X 2$ sequences, called, respectively, StAOX1a, StAOX1b, StAOX1d and StAOX2 according to the AOX classification proposed by Costa et al. (2014). All StAOX isoforms were expressed but harbored tissue specificity in our experimental conditions (Supplementary Figure S3). The $R$. irregulare genome contained one single AOX sequence (RiAOX).

Two isoforms encoding for cytochrome $c$ (StCytc1 and StCytc2) and COXVb (StCOXIVb1 and StCOXIVb2) were found in $S$. tuberosum genome, but StCytc2 was not expressed in the roots and therefore it was not considered for further analysis (Supplementary Figure S3). The R. irregulare genome contained one single gene encoding for cytochrome $c$ (RiCytc) and COXVb (RiCOXIVb).

The expression of six (StPT1, 2/6, 3, 4, 5, and 8) out of the ten previously described PT genes belonging to the Pht1 family in S. tuberosum (Leggewie et al., 1997; Rausch et al., 2001; Nagy et al., 2005; Chen et al., 2014) was studied. The expression of StPT2 and StPT6 was not dissociable and was considered as a sum StPT2/6. These two genes shared a very high sequence similarity and are tandemly organized on chromosome 3 . On chromosome 6, only two complete sequences were found in potato: StPT7 sequence was incomplete and could not be reconstructed in silico. StPT8, StPT9, and StPT10 were all located in the same region of the chromosome 9. The expression of StPT8, which shares the highest homology with SIPT7 (Chen et al., 2014), was studied. In R. irregulare, the Pht1 family was divided into four different clusters named after the $S$. cerevisiae sequences therein (Supplementary Figure S4). ScPHO84-like cluster groups had putative high affinity $\mathrm{P}$ transporters as $\mathrm{ScPHO} 84$ and contained four putative R. irregulare sequences previously described (RiPT1, RiPT2, RiPT3, and RiPT4; Fiorilli et al., 2013; Walder et al., 2016). We found complete and functional sequences only for RiPT1 and RiPT3. Within the putative low affinity $\mathrm{P}$ transporters, grouping with the yeast transporters ScPHO87 and ScPHO90 described by Pinson et al. (2004), only one $R$. irregulare gene was found (RiPT7). The third cluster groups sequences presented homology with the $S$. cerevisiae high affinity $\mathrm{Na}^{+} / \mathrm{Pi}$ cotransporter ScPHO89 (Sengottaiyan et al., 2013) and two $R$. irregulare sequences (RiPT5 and RiPT6). RiPT6 presented an incomplete sequence and no expression in our experimental conditions. The last cluster contained ScPHO88-like sequences, which were much shorter (about 189 aa) and did not present a transport activity. One $R$. irregulare gene matched with this sequence (RiPT8), but as it did not encode a functional transporter, the transcription of this gene was not monitored in this study.

Concerning mitochondrial $\mathrm{P}$ transport, four gene sequences encoding a transporter were found in $S$. tuberosum genome, and one $R$. irregulare in genome (Supplementary Figure S5). In potato, three of the four genes were expressed in roots (StMPT1a, StMPT1b, and StMPT3). StMPT2 was found to be expressed only in fruits in our experimental conditions (Supplementary Figure S3).

Then, two $l d h$ and three $p d c$ sequences were found in potato genome (Supplementary Figures S6 and S7). It was noted that transcript level was higher for StLDH expression than for StPDC in root, comparing relative values. One $l d h$ sequence was found in the $R$. irregulare genome $(R i L D H)$.

\section{Experiment 2: Influence of ABA on Mycorrhizal Behavior and Expression Pattern of Genes Involved in Mitochondrial Electron Chain}

Following ABA pretreatment, mycorrhizal structures were observed in the primary adventitious root and even in the stem base (Figures 2A-D), which seems to be a rare case in potato roots under normal conditions (Mercy - non-published observation). AMF increased plant total FW biomass in nonpretreated plants by 1.26 -fold $(\mathrm{MGD}=20.6 \%)$ and in $\mathrm{ABA}$ pretreated plants by $7.33(\mathrm{MGD}=86.4 \%)$. Pretreatment with ABA during the in vitro phase induced a long-term effect, since a strong plant growth depression was observed (in NM plants, Figure 2E). Mycorrhizal colonization and arbuscule intensity were significantly promoted within ABA pretreated plants (Figure 2F) compared to non-pretreated plants, consistent 
A

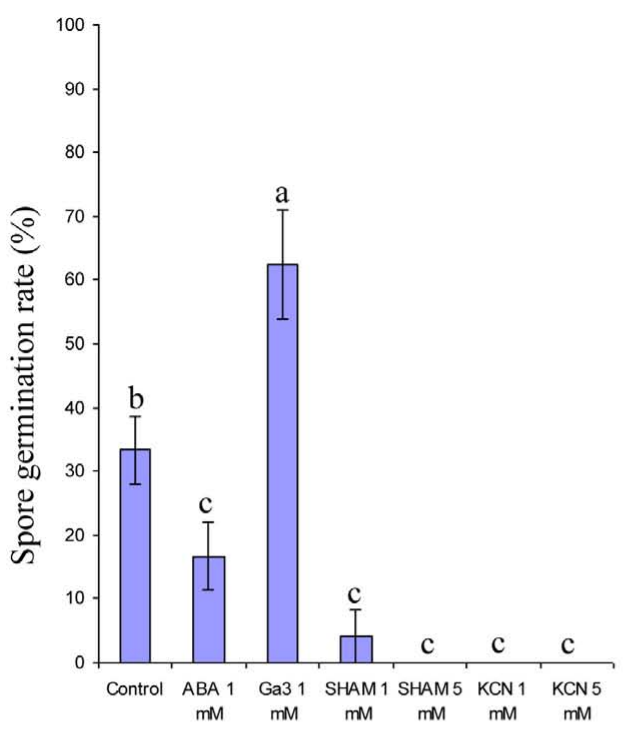

B

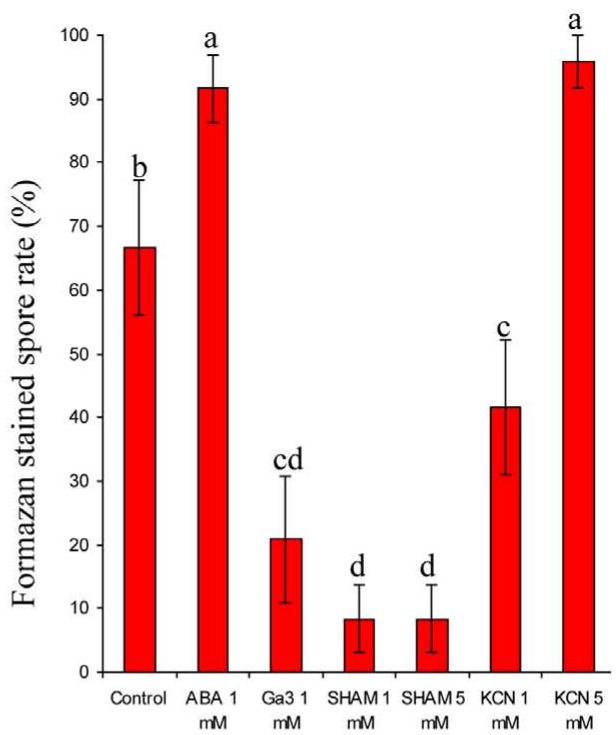

C

D
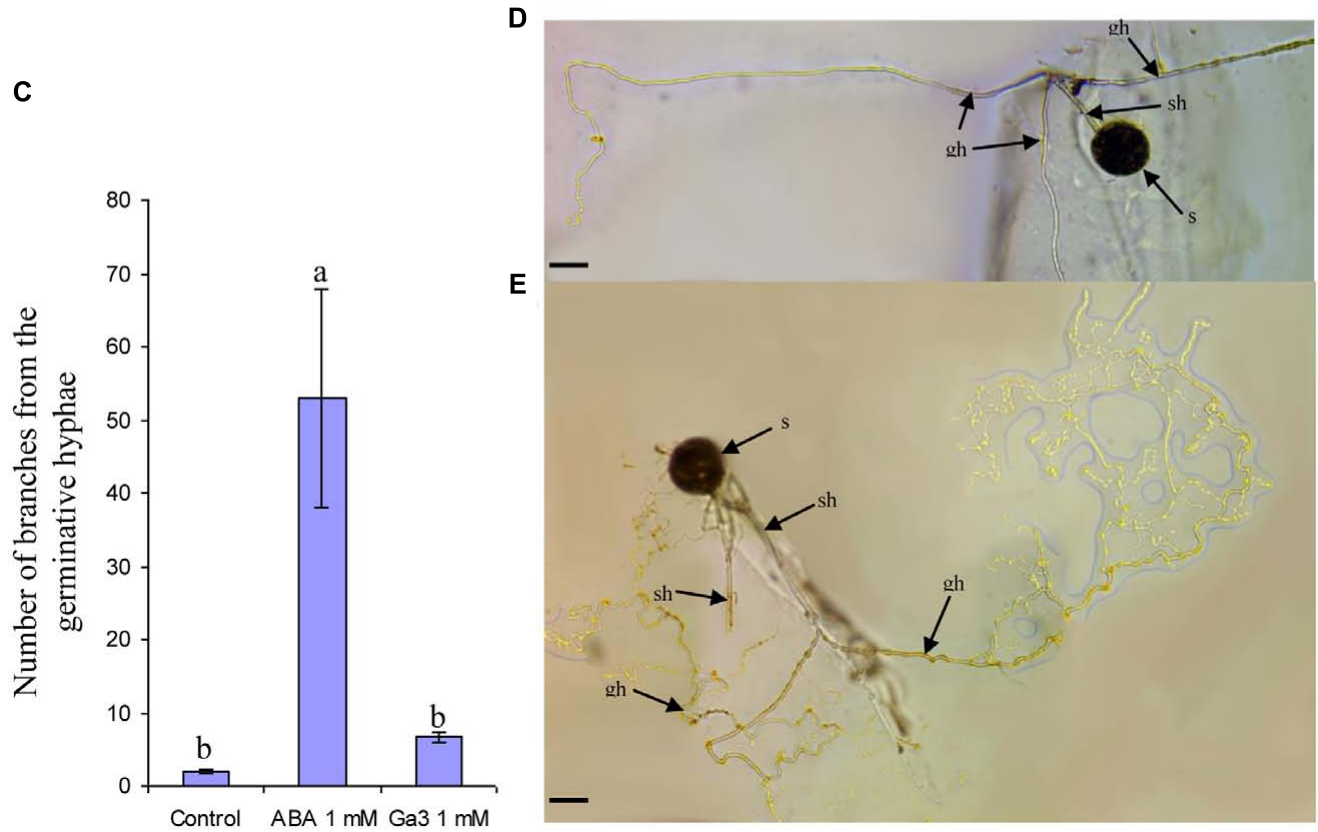

FIGURE 1 | Effect of two antagonistic plant growth regulators and two respiratory inhibitors on spore germination, spore viability, and germinative hyphal phenotype. Effect of Ga3 (1 mM), ABA (1 mM), SHAM (1 and $5 \mathrm{mM}$ ) and KCN (1 and $5 \mathrm{mM}$ ) on spore germination (R. irregulare) (A) and spore viability (B), number of branches in the germinative hyphae following or not ABA and Ga 3 treatment (C) with representative germinative straight hyphal pattern under Ga3 treatment (D) or branched hyphal pattern under ABA treatment (E). s, spore; sh, subtending hypha; gh, germinative hypha. Data show means $(n=24) \pm \mathrm{SE}$ Treatments with the same letter are not significantly different $(p<0.05$ SNK multiple-comparison ANOVA), after arcsin transformation of percentage values. Scale bar: $50 \mu \mathrm{m}$. Data analysis was performed with the SAS enterprise guide 4.1 (SAS Institute Inc., Cary, NC, USA).

with observations performed on tomato plants (Herrera-Medina et al., 2007).

The expression analyses of genes involved in the respiratory chain revealed that StAOX1d and StAOX2 were significantly down-regulated while $S t C y t c 1$ was significantly up-regulated in $\mathrm{M}$ versus $\mathrm{NM}$ plants in presence of ABA (Figure 2G). The expression of these genes remained unaffected by the presence of AMF and in the absence of treatment. Comparing to NM and $\mathrm{M}$ non-treated plants, ABA treatment induced similar trends of up-regulation for StAOX1d and StAOX2 (although changes are not significant), while $S t C y t c 1$ was down-regulated (significant when comparing NM plants). Contrasting with this observation, 


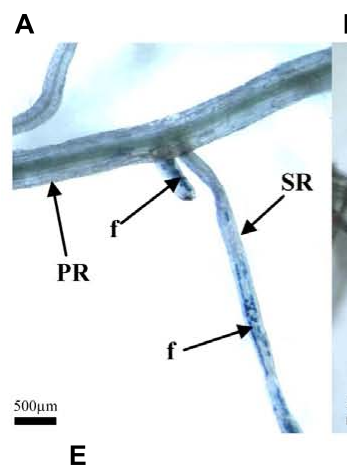

E

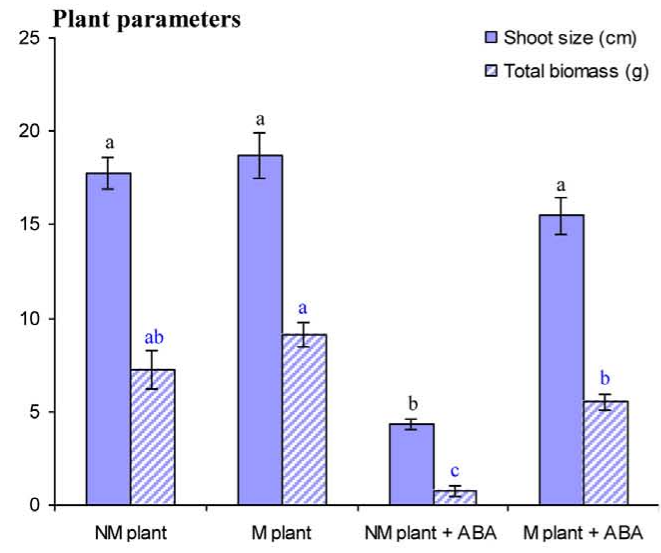

G

Fold change of genes involved in mitochondrial respiratory chain and fermentation in Solanum tuberosum (relative value)

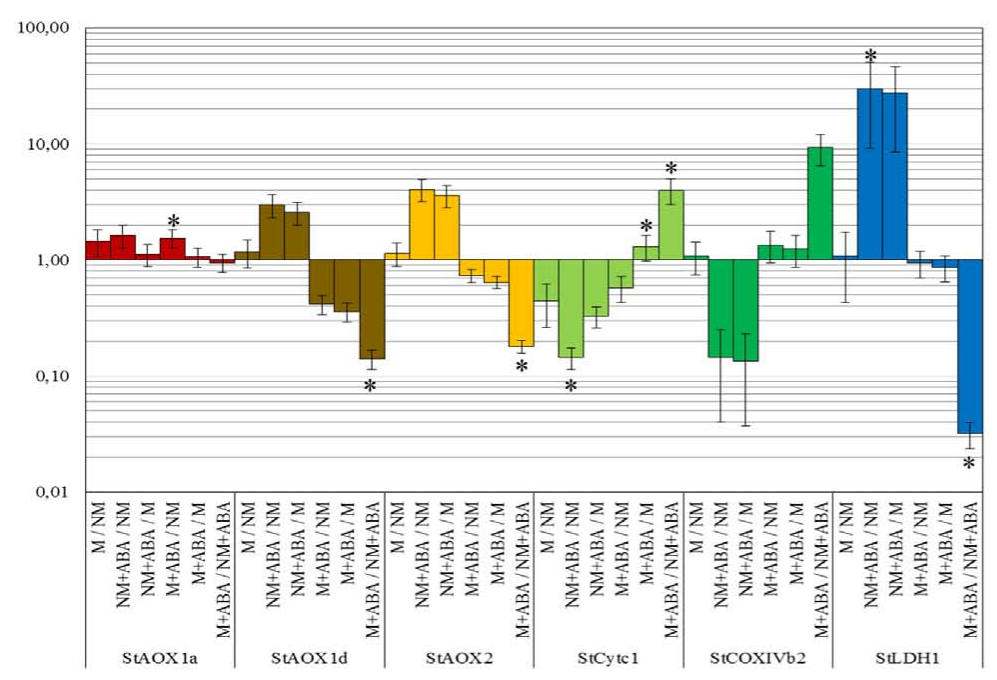

D

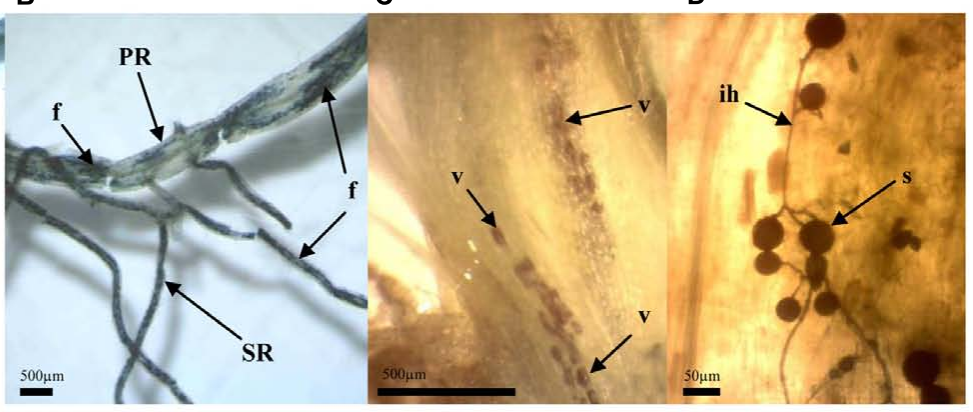

F

Mycorrhizal rate (\%)

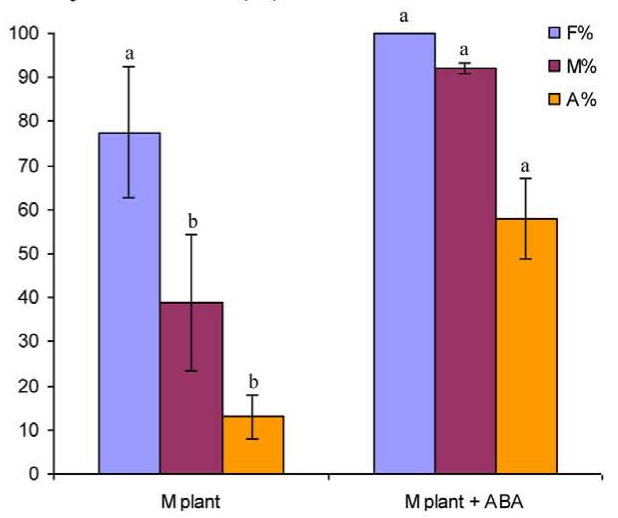

H

Fold change induced by ABA relative to non treated plants in Rhizoglomus irregulare (relative value)

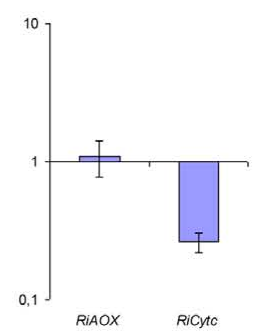

FIGURE 2 | Influence of ABA on mycorrhizal development and gene expression involved in electron partitioning. Mycorrhizal development (R. irregulare) observed at 8 WAl in potato roots (CV. KK19-0012) pre-treated or not with ABA (0.1 mM) during the in vitro phase culture. (A) typical fungal development in plants non-treated with $A B A$ (B) typical fungal development in plants pretreated with $A B A ;(C, D)$ mycorrhizal development on a stem of ABA pretreated plant; (E) growth parameters of potato plant inoculated or not with $R$. irregulare after ABA pretreatment or not (8 WAl); (F) mycorrhizal rate between inoculated plant treated (M plant + ABA) or not pretreated (M plant) with ABA; $(\mathbf{G}, \mathbf{H})$ : expression pattern of genes involved in electron partitioning. PR, primary adventitious root; SR, secondary adventitious root; $\mathrm{f}$, mycorrhizal structure; $\mathrm{v}$, vesicle; s, spore; ih, intraradical hypha; F\%, frequency of mycorrhizal development in root system; M\%, intensity of mycorrhizal development in the root; A\%, intensity of arbuscule development in whole root system. For plant and fungal parameters, treatments with the same letter are not significantly different $(P<0.05$ SNK multiple-comparison ANOVA, $n=4)$. Statistical tests were performed separately for each plant parameters and each fungal parameters, after arcsin transformation for percentage values. For expression data $\mathbf{( G , H )}$, significant difference are indicated by stars above graphs $\left({ }^{*} P<0.05\right)$. Data analysis was performed with the SAS enterprise guide 4.1 (SAS Institute Inc., Cary, NC, USA). 
the presence of AMF in ABA plants induced significant downregulation for StAOX1d and StAOX2 and up-regulation for StCytc1 (significant) and CoxIVb2 (tendency) when compared to non-inoculated ABA plants. It was observed a strong up regulation of StLDH1 induced by ABA compared to non-treated plants, inoculated (tendency) or not (significant). This gene was significantly down-regulated in presence of AMF (within ABA plants group). Regarding RiAOX and RiCytc (Figure $\mathbf{2 H}$ ), no significant effect induced by ABA was observed, although RiCytc tended to be down-regulated.

\section{Experiment 3}

\section{The Fungal Colonization Is Influenced by Phosphorus Level and Respiratory Inhibitors}

Fungal phenotypic data are indicated in Figure 3 and Supplementary Figure S1. The mycorrhizal colonization decreased with increasing $\mathrm{P}$ concentrations in all treatments. Many fungal structures, such as hyphae, arbuscules, vesicles, and frequency of mycorrhiza, were affected by KCN and SHAM, especially under low $\mathrm{P}$ concentration (1 and $10 \mathrm{ppm}$, Figure 3 and Supplementary Figure S1). Compared to non-treated mycorrhizal plants ( $M$ plants), SHAM treatment significantly reduced the arbuscule (A \%) formation to the benefit of an enhanced intraradical hyphal development (h \%, Figure 3 ). KCN treatment strongly inhibited the fungal development at 1 and $10 \mathrm{ppm}$ P (Supplementary Figure S1), but a significant higher a $\%$ was observed (Figure 3) compared to SHAM among $\mathrm{P}$ concentrations. At $300 \mathrm{ppm} \mathrm{P}$, highest values were observed for almost all fungal parameters under KCN treatment (Supplementary Figure S1). Hyphal development (H \%) in $\mathrm{M}$ KCN was reduced compared to M and M SHAM plants at 1 and 10 ppm P (Figure 3).

\section{The Mycorrhizal Type Is Influenced by Phosphorus Level and Respiratory Inhibitors}

Both Arum-type and Paris-type structures were observed in roots (Figures 4A,B, respectively) across the different treatments, and their occurrences were influenced by both $\mathrm{P}$ concentrations and respiratory chain inhibitors (Figure 4C). In M plants, Arum-type predominated under low $\mathrm{P}$ concentrations (1 to $50 \mathrm{ppm}$ ) while Paris-type predominated at high $\mathrm{P}$ concentration $(300 \mathrm{ppm})$. The application of both respiratory inhibitors suppressed this $\mathrm{P}$ influence. SHAM treatment induced a disorganization of arbuscule branching similar to the effect of a high $\mathrm{P}$ concentration (300 ppm P) in non-treated plants and Paris-type hyphal development was predominant for all $\mathrm{P}$ concentrations. Under KCN treatment, Arum-type was predominant for all $\mathrm{P}$ concentrations. The occurrence of Arum-type in $\mathrm{KCN}$ was significant compared to Paris-type in SHAM for all $\mathrm{P}$ concentrations.

\section{The Spore Production Is not Linked to either with $\mathrm{P}$ Concentrations, nor with Mycorrhizal Rate}

A maximum number of spores was observed at $50 \mathrm{ppm} \mathrm{P}$ (Figure 5), and then in a lesser extent, at $1 \mathrm{ppm}$. The number of spores produced at 10, 100 and 300 ppm P was similar, and significantly lower than at 1 and $50 \mathrm{ppm}$ P. No correlation between spore production and $\mathrm{P}$ concentration was observed $\left(r^{2}=0.1834\right)$. No correlation between spore production and any mycorrhizal parameters was observed among P concentrations, which might indicate the involvement of at least two different metabolic determinants. We noticed that highest values for spore number, a \% and Arum-type were obtained at 1 and $50 \mathrm{ppm}$ P.

\section{Respiratory Chain Inhibitors Reveal Opposite Plant Performance between Inoculated and Non-inoculated Plants}

Plant phenotypic data are indicated in Figure 6 and Supplementary Figure S2. Presence of AMF in non-treated plants induced few specific responses to $\mathrm{P}$ concentrations on plant vegetative parameters including shoot and root biomass, yield and total biomass. Only shoot size was significantly promoted among $\mathrm{P}$ concentrations (Figure 6).

Under KCN treatment, the presence of AMF significantly improved all vegetative plant parameters under all $P$ concentrations, whereas under SHAM treatment, root biomass, yield and total biomass were decreased (Figure 6). Thus, KCN and SHAM treatments had opposite effects when comparing inoculated and non-inoculated plants for yield and FW total biomass. M KCN plants showed the highest root FW values at $300 \mathrm{ppm} \mathrm{P}$ with an increase of 2.34- and 4.24-fold, respectively, compared to $\mathrm{M}$ and $\mathrm{M}$ SHAM plants (Supplementary Figure S2).

We noticed that the tuber FW yield was not proportional to $\mathrm{P}$ concentrations in several treatments (Supplementary Figure S2): a peak was observed in NM, M and $\mathrm{KCN}$ plants at $50 \mathrm{ppm}$ $\mathrm{P}$, while maximum values were obtained at $100 \mathrm{ppm} \mathrm{P}$ in M SHAM plants. Similarly, the total biomass FW increase among $\mathrm{P}$ concentration was not proportional in NM plants where a peak was observed at $50 \mathrm{ppm} \mathrm{P}$, but not in $\mathrm{M}$ plants. FW biomass data revealed that $\mathrm{AMF}$ had an impact on plant FW biomass partitioning (Figures 7A-C). The percentage of FW attributed to the root part was relatively stable for a given treatment among $\mathrm{P}$ concentrations, with the exception of NM plants (Figure 7A) at $10 \mathrm{ppm}$ (higher value). When non-treated plants were inoculated with AMF, the profile of the FW percentage attributed to the shoot was opposite to the one attributed to the tuber yield and an anomaly was observed at $50 \mathrm{ppm}$ P. In all treatments and P concentrations, except SHAM plants at $10 \mathrm{ppm} \mathrm{P}$, the presence of AMF enhanced FW biomass allocation to the yield, to the detriment of the shoot.

\section{Impact of Respiratory Inhibitors on the Mycorrhizal Yield Dependency}

The mycorrhizal dependency was affected by $\mathrm{P}$ in $\mathrm{M}$ plants without any direct correlation with the concentration (Figure 8), as the maximum value was observed at 1 ppm $\mathrm{P}$ (63.05\%) and the lowest at $10 \mathrm{ppm} \mathrm{P}(-12.48 \%)$. The higher $\mathrm{P}$ concentration yielded low but positive values. The mycorrhizal dependency presented an opposite pattern between KCN and SHAM treatments. The yield formed under KCN conditions was almost totally dependent (close to 100\%) of the presence of AMF, and the lowest value was observed at $50 \mathrm{ppm}$. In contrast, with 


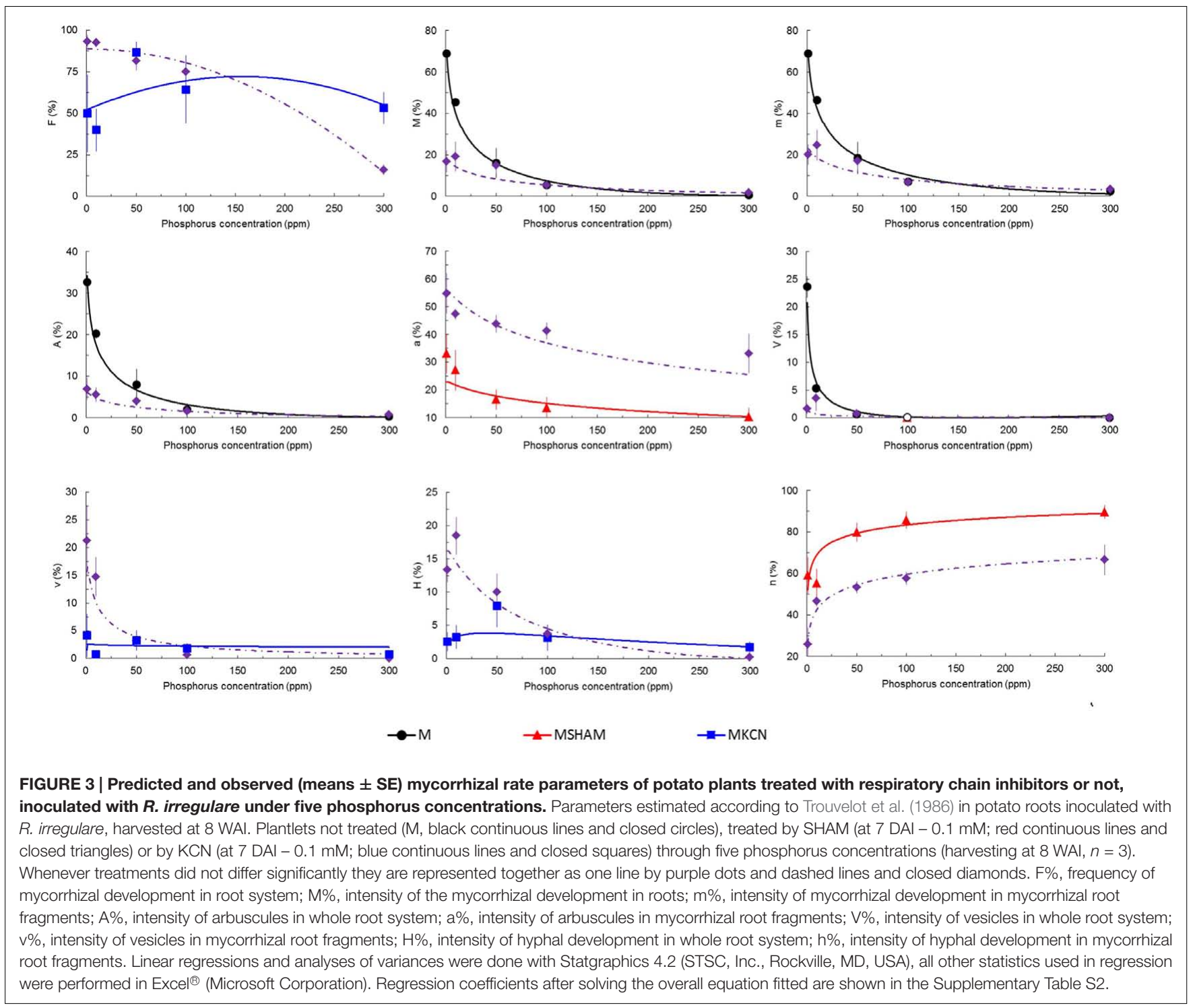

the exception of 1 ppm $\mathrm{P}$, a negative mycorrhizal yield response was observed in SHAM treatment in all P concentrations tested.

\section{Modulation of Genes Involved in Mitochondrial Electron Chain and Fermentation by Phosphorus and Respiratory Inhibitors}

Variation of the expression of genes involved in the respiratory chain and fermentation among $\mathrm{P}$ concentrations (1 ppm used as reference) for each treatment, in potato and $R$. irregulare, are indicated in Figure 9 and Supplementary Figures S8, S9.

At plant side, data showed that the regulation pattern from genes encoding for $\mathrm{AOX}, \mathrm{COX}$, or fermentation pathways were mostly specific to the $\mathrm{P}$ concentration (such as a down-regulation of StAOX1a at $100 \mathrm{ppm}$ in NM plants, an up-regulation of StAOX1d in NM KCN plants at $50 \mathrm{ppm}$ or a down-regulation of StCOXIVb2 in M SHAM plants at $100 \mathrm{ppm}$ ). We noticed that a significant common up-regulation was observed at $50 \mathrm{ppm} P$ for genes involved in cytochrome pathway (StCytc1, StCOXVb1-2) in non-inoculated plants but not in inoculated plants (non-treated group). Specific responses to $\mathrm{P}$ concentration were also noted for genes involved in fermentation. We observed that StPDC1 in M plants was more expressed and StLDH1 was more repressed in M $\mathrm{KCN}$ with increasing $\mathrm{P}$ concentrations.

Within R. irregulare, some transcript variations were observed at specific $\mathrm{P}$ concentrations but the tested genes were mostly unaffected. In $\mathrm{M}$ plants, when compared to $1 \mathrm{ppm} \mathrm{P}$, a significant up-regulation was observed at $50 \mathrm{ppm}$ for RiAOX, while RiCytc harboured an opposite profile pattern (although not significant). These data were concomitant with the highest sporulation (Figure 5). In contrast with non-treated conditions, a significant down-regulation was observed at $50 \mathrm{ppm}$ for RiAOX in M KCN plants. It is noteworthy that no detection was obtained at $300 \mathrm{ppm}$ P from M plants.

Variation of the expression of genes involved in the respiratory chain and fermentation between treatments (non-inoculated plants used as reference) for each $\mathrm{P}$ concentration, in potato 

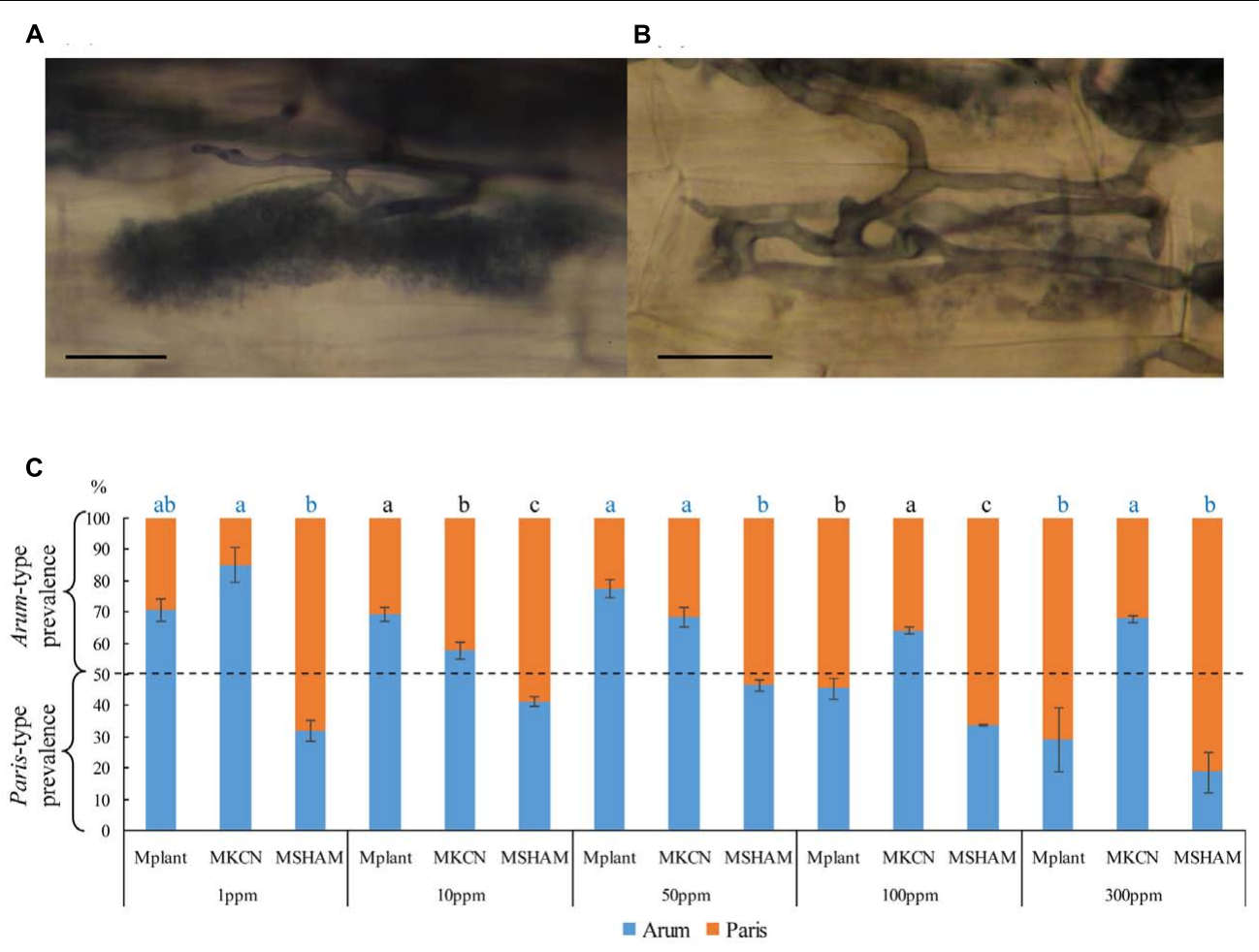

\begin{tabular}{|l|l|l|l|l|l|}
\hline \multicolumn{6}{|l|}{ Level of significance among P concentrations } \\
\hline Treatment & $1 \mathrm{ppm} \mathrm{P}$ & $10 \mathrm{ppm} \mathrm{P}$ & $50 \mathrm{ppm} \mathrm{P}$ & $100 \mathrm{ppm} \mathrm{P}$ & $300 \mathrm{ppm} \mathrm{P}$ \\
\hline Mplant & a & a & a & b & b \\
\hline MKCN & a & b & b & b & b \\
\hline MSHAM & ab & a & a & ab & b \\
\hline
\end{tabular}

FIGURE 4 | Mycorrhizal type's prevalence within potato roots, following treatments or not with respiratory chain inhibitors, under five phosphorus concentrations. Mycorrhizal types within potato roots: (A) Arum-type, (B) Paris-type (staining: China Ink); (C) percentages of mycorrhizal type distribution under five different phosphorus concentrations in non-treated control plants and plants treated by respiratory inhibitors. Scale bar: $10 \mu \mathrm{m}$. Data show means $(n=3) \pm \mathrm{SE}$. Treatments with the same letter are not significantly different $(P<0.05$, Duncan's multiple range tests ANOVA). Statistical tests were performed after arcsin transformation of percentage values. The level of significance among treatment per $\mathrm{P}$ concentration is given above the graphs, and the one among $\mathrm{P}$ concentrations for a given treatment is indicated in the table below graph. Data analysis was performed with the SAS enterprise guide 4.1 (SAS Institute Inc., Cary, NC, USA).

and $R$. irregulare, are indicated in Figure $\mathbf{1 0}$ and Supplementary Figures S10, S11.

In potato, transcript responses for genes encoding for enzymes involved in the AOX and COX pathways were mostly specific to $\mathrm{P}$ concentration. In particular, the presence of AMF compared to their absence (non-treated plants) at $50 \mathrm{ppm} \mathrm{P}$ induced an up-regulation of StAOX2 but a down-regulation of StCytc1. Effect of treatments on the expression of genes involved in fermentation pathway were also specific to $\mathrm{P}$ concentration. Significant up-regulation was observed for StPDC1 and StLDH1 when comparing KCN to SHAM treatments (in plants inoculated or not), but with some specificities regarding $\mathrm{P}$ concentrations.

In the fungus, expression levels of RiAOX, RiCytc, or $\mathrm{RiCOXIVb}$ appeared mostly constitutive when comparing $\mathrm{KCN}$ to SHAM treatments. In contrast, $\mathrm{KCN}$ induced significant strong up-regulation of RiLDH at 1, 50, and 300 ppm P compared to SHAM.

To summarize, the inoculation or the use of respiratory inhibitors induced specific expression patterns for genes encoding for enzymes involved in the AOX and COX pathways, but StAOX isoforms were unexpectedly not highly induced by KCN compared to SHAM treatments. No obvious interpretation can be easily deduced from these data, underlining complex regulations that were contrasted with those obtained in the Experiment 2. We noticed, nevertheless, that $\mathrm{KCN}$ seemed to induce a higher fermentation context compared to SHAM, within potato (inoculated or not) and also in R. irregulare.

Several correlations were found between expression of genes and fungal parameters in non-treated plants (Supplementary Table S4) or treated with KCN (Supplementary Table S5) or with SHAM (Supplementary Table S6). Significant negative correlations were observed between $\mathrm{M} \% \mathrm{~m} \%$, A \%, and $\mathrm{V} \%$ and StAOX2, but a positive correlation with the $\mathrm{H} \%$ parameter (non-treated plants) was found. Significant negative correlations were also noticed between StCytc1 and F \% and a \%, between StCOXVb1 and F \% and between StCOXVb2 and $\mathrm{h} \%$. Under KCN, positive 


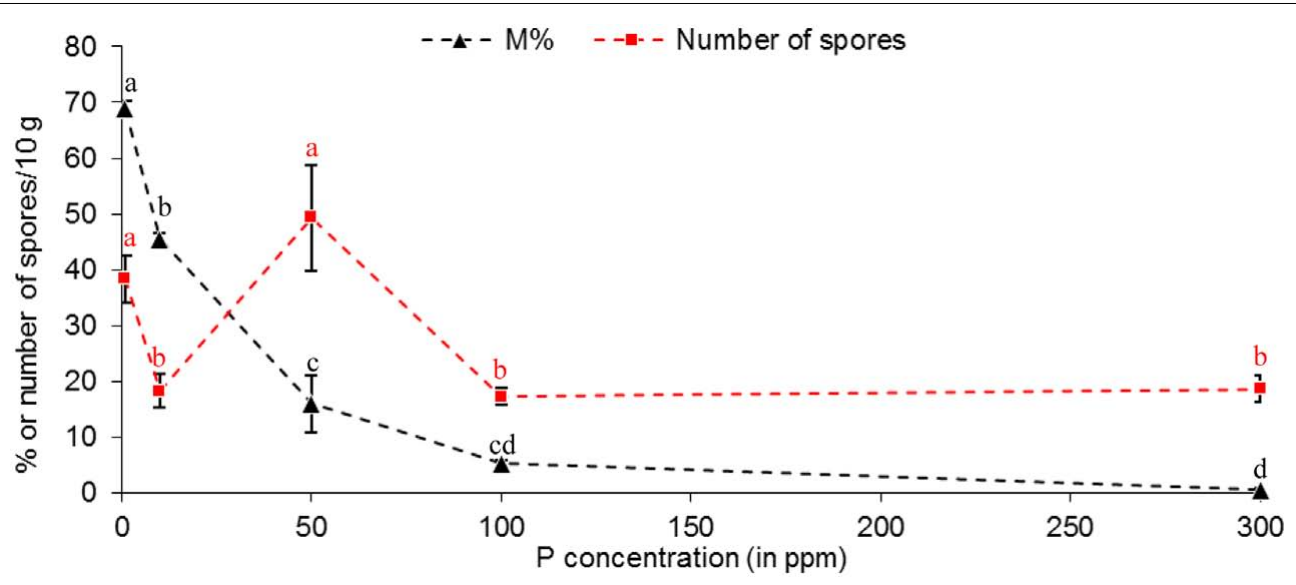

FIGURE 5 | Effect of phosphorus concentrations in non-treated plants on mycorrhizal sporulation, compared to mycorrhizal development in root. R. irregulare spore number in $10 \mathrm{~g}$ of substrate and intensity of mycorrhiza in root ( $\mathrm{M} \%$, added only to visualize the differences with sporulation profile) at 8WAI through phosphorus concentration after inoculation of potato in vitro plantlets. Data show means $(n=3) \pm$ SE. Treatments with the same letter are not significantly different $(P<0.05$, Duncan's multiple range tests ANOVA). Statistical tests were performed separately for each fungal parameter, and after arcsin transformation of percentage values (M \%). Data analysis was performed with the SAS enterprise guide 4.1 (SAS Institute Inc., Cary, NC, USA).
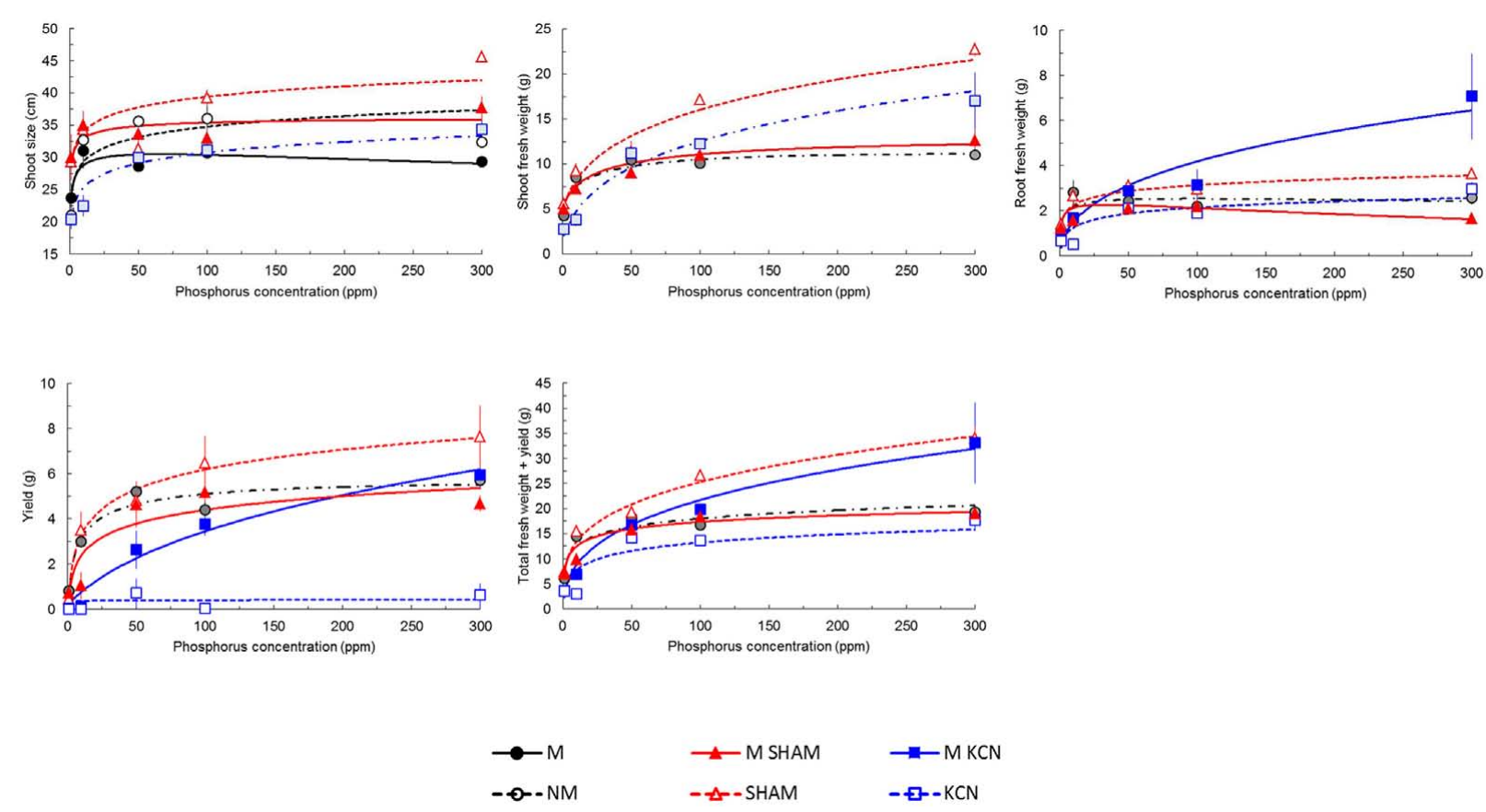

FIGURE 6 | Predicted and observed (means \pm SE) of potato in vitro plantlets growth parameters treated with respiratory chain inhibitors or not and inoculated or not with $\boldsymbol{R}$. irregulare under five phosphorus concentrations. Plantlets were inoculated (M, black continuous lines and closed circles) or not (NM, black dashed lines and open circles) with $R$. irregulare, treated by SHAM (at 7 DAl $-0.1 \mathrm{mM}$ ) and inoculated (M SHAM, red continuous lines and closed triangles) or not (SHAM, red dashed lines and open triangles), and treated by KCN (at $7 \mathrm{DAl}-0.1 \mathrm{mM}$ ) and inoculated (M KCN, blue continuous lines and closed squares) or not (KCN, blue dashed lines and open squares) through five phosphorus concentrations (harvesting at $8 \mathrm{WAl}, n=3$ ). Whenever M and NM treatments did not differ significantly for a given treatment same colors and symbols were used except that dots and dashed lines and half tone symbols were used. Linear regressions and analyses of variances were done with Statgraphics 4.2 (STSC, Inc., Rockville, MD, USA), all other statistics used in regression were performed in Excel $^{\circledR}$ (Microsoft Corporation). Regression coefficients after solving the overall equation fitted are shown in Supplementary Table S3.

correlations were observed between StAOX1a and A \% and $\mathrm{V} \%$ and also between StAOX1d and A \% but a negative correlation between StAOX1d and $\mathrm{H} \%$ was detected. Under SHAM, a significant negative correlation was found between $\mathrm{F} \%$ and StAOX1d. No correlation was found between tested genes involved in AOX or COX pathway with mycorrhizal responses on plant phenotype in any treatment. 

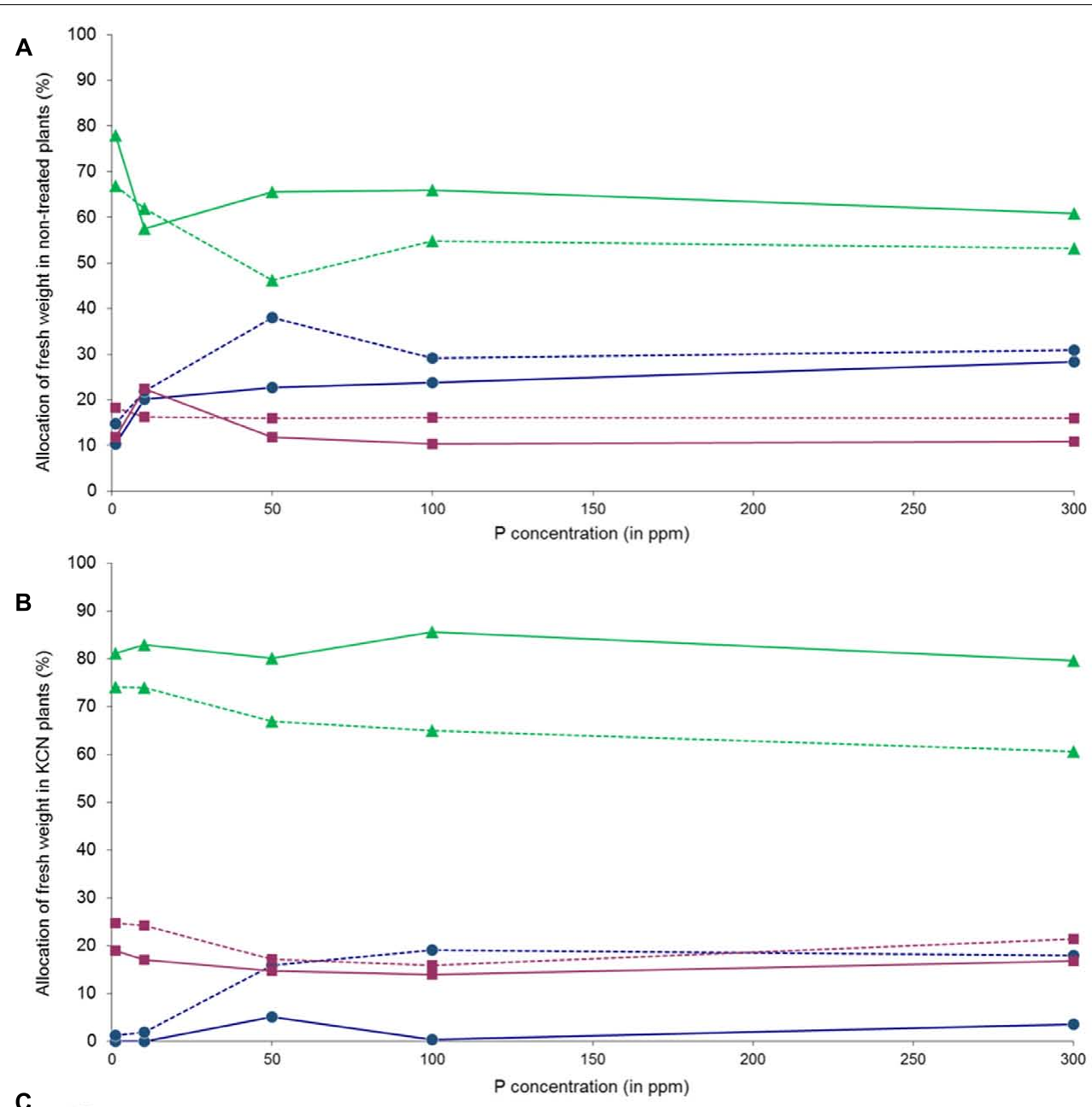

\section{C}

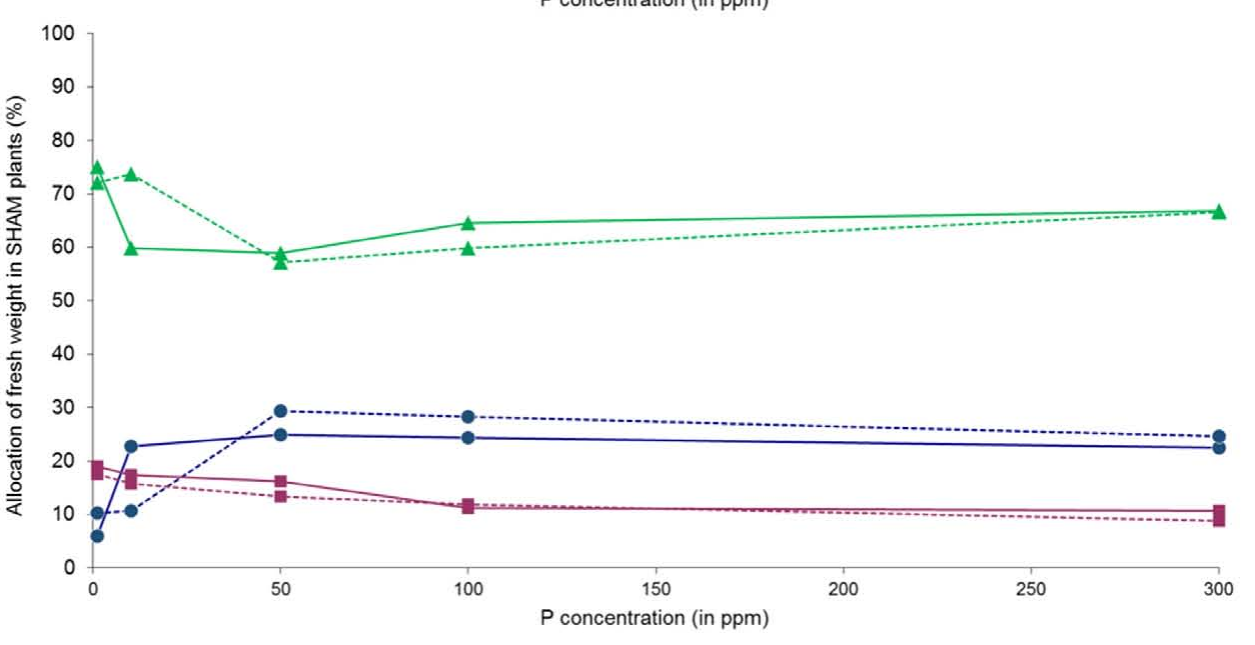

$$
\begin{aligned}
& -\bullet \text { Yield NM plants } \rightarrow \text { Shoot NM plants } \rightarrow \text { Root NM plants } \\
& \ldots-\text {--Yield M plants } \quad \ldots-\text { Shoot M plants } \quad-\cdots \text { Root M plants }
\end{aligned}
$$

FIGURE 7 | Percentage of FW attributed to the shoot, root and tuber in potato in vitro plantlets. Plants are inoculated with $R$. irregulare (A) without treatment; (B) treated by KCN (at $7 \mathrm{DAl}-0.1 \mathrm{mM}$ ); (C) treated by SHAM (at $7 \mathrm{DAl}-0.1 \mathrm{mM}$ ) through five phosphorus concentrations (data obtained after 8 WAl). 


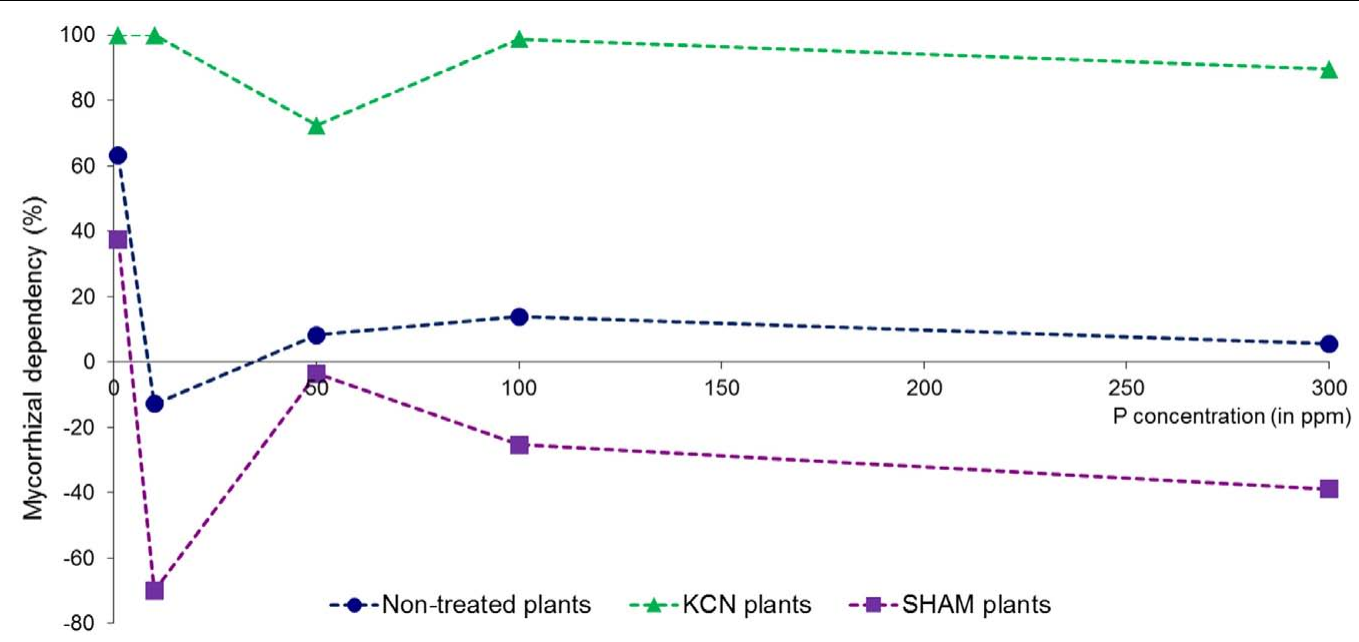

FIGURE 8 | Mycorrhizal growth dependency (yield) in potato in vitro plantlets. Plants are inoculated with R. irregulare without treatment or treated by SHAM (at $7 \mathrm{DAl}-0.1 \mathrm{mM}$ ) or treated by $\mathrm{KCN}$ (at $7 \mathrm{DAl}-0.1 \mathrm{mM}$ ) through five phosphorus concentrations (data obtained after 8 WAl).

\section{Modulation of Genes Involved in Nutrient and Proton Transport by Phosphorus and Respiratory Inhibitors}

Variation of the expression of genes involved in nutrient and proton transport among $\mathrm{P}$ concentrations (1 ppm used as reference) for each treatment, in potato and $R$. irregulare, are indicated in Figure 9 and Supplementary Figures S8, S9.

In potato, a common expression pattern was observed at 300 ppm P for StPT3, StPT4, StPT5, StAMT4, StAMT5, and StHA5, which were up-regulated in NM plants but repressed in $\mathrm{M}$ plants. This response was much less pronounced in plants inoculated and treated with SHAM and disappeared in the other treatments (NM KCN, M KCN, and NM SHAM). StPT1 remained mostly unaffected by inoculation or treatment, StPT2/6 was down-regulated by high $\mathrm{P}$ in $\mathrm{M}$ plants treated or not with respiratory inhibitors, but also in NM SHAM plants. Some specific responses were obtained depending on $\mathrm{P}$ concentration and treatment for StPT8.

Concerning mitochondrial P transport, StMPT1a expression in NM plants tended to increase with $\mathrm{P}$ concentration, from 10 to $300 \mathrm{ppm}$, although no significant variations were observed when comparing the various $\mathrm{P}$ concentrations to $1 \mathrm{ppm} \mathrm{P}$. SHAM treatment tended to up-regulate this gene at high $\mathrm{P}$ concentrations (50 to $300 \mathrm{ppm}$ ). StMPT1b was up-regulated by high $\mathrm{P}$ in plants non-treated (non-inoculated) or treated by SHAM (inoculated or not).

Variation of the expression of genes involved in nutrient and proton transport between treatments (non-inoculated plants used as reference) for each $\mathrm{P}$ concentration, in potato and $R$. irregulare, are indicated in Figure $\mathbf{1 0}$ and Supplementary Figures S10, S11.

At plant side, as common response, the presence of AMF, in plants treated or not with respiratory inhibitors, up-regulated the expression of StPT3, StPT4, StPT5, StAMT4, StAMT5, and StHA5 for all $\mathrm{P}$ concentrations, except at $300 \mathrm{ppm}$ within nontreated plants. Such strong responses were not found for StPT1, StPT2/6, and StPT8 in any treatment. In KCN plants, presence of AMF was associated with up-regulation of StPT1 at 1, 50, and $100 \mathrm{ppm}$ P and StPT2/6 at $100 \mathrm{ppm}$ P, compared to plants treated or not with SHAM. Significant strong correlations were found between AM-inducible P transporters and $\mathrm{M} \%$ or A \% (in plants treated or not with SHAM, Supplementary Tables S4, S6) but most of these correlations were not observed in plants treated with KCN (Supplementary Table S5). Tested genes involved in mitochondrial transport were up-regulated in presence of AMF in non-treated plants in all $\mathrm{P}$ concentrations, but responses were specific to the isoform. In the presence of respiratory inhibitors, their expression patterns were more complex with specific responses regarding $\mathrm{P}$ concentration.

The expressions of RiPT1, RiPT7, and RiHA5 were monitored in this study and highlighted that there were no transcript level changes across all treatments and $\mathrm{P}$ concentrations (Figure 9). Only RiPT5 was induced at high $\mathrm{P}$ conditions with an upregulation at 50 and $100 \mathrm{ppm} \mathrm{P}$ in control conditions. Regarding RiMPT, when compared to $1 \mathrm{ppm}$, a significant up-regulation was observed at $300 \mathrm{ppm} \mathrm{P}$ (Figure 9) in plants treated with SHAM, and non-treated plants at $100 \mathrm{ppm} \mathrm{P}$, and a significant down-regulation was observed at $300 \mathrm{ppm}$ when comparing $\mathrm{KCN}$ to SHAM (Figure 10).

\section{DISCUSSION}

\section{Mitochondrial Respiratory Inhibitors Influence Fungal Behavior at Pre-symbiotic Phase}

Dormancy is often related to AOX pathway in plant seeds, but also in fungi. Several examples have been reported, especially within Mucoromycotina (Cano-Canchola et al., 1988; SalcedoHernandez et al., 1994) which are phylogenetically closely related to AMF (Hibbett et al., 2007), showing a respiratory shift characterizing spore germination process from AOX (dormancy) to COX (hyphal growth). It is difficult to define AOX/COX 


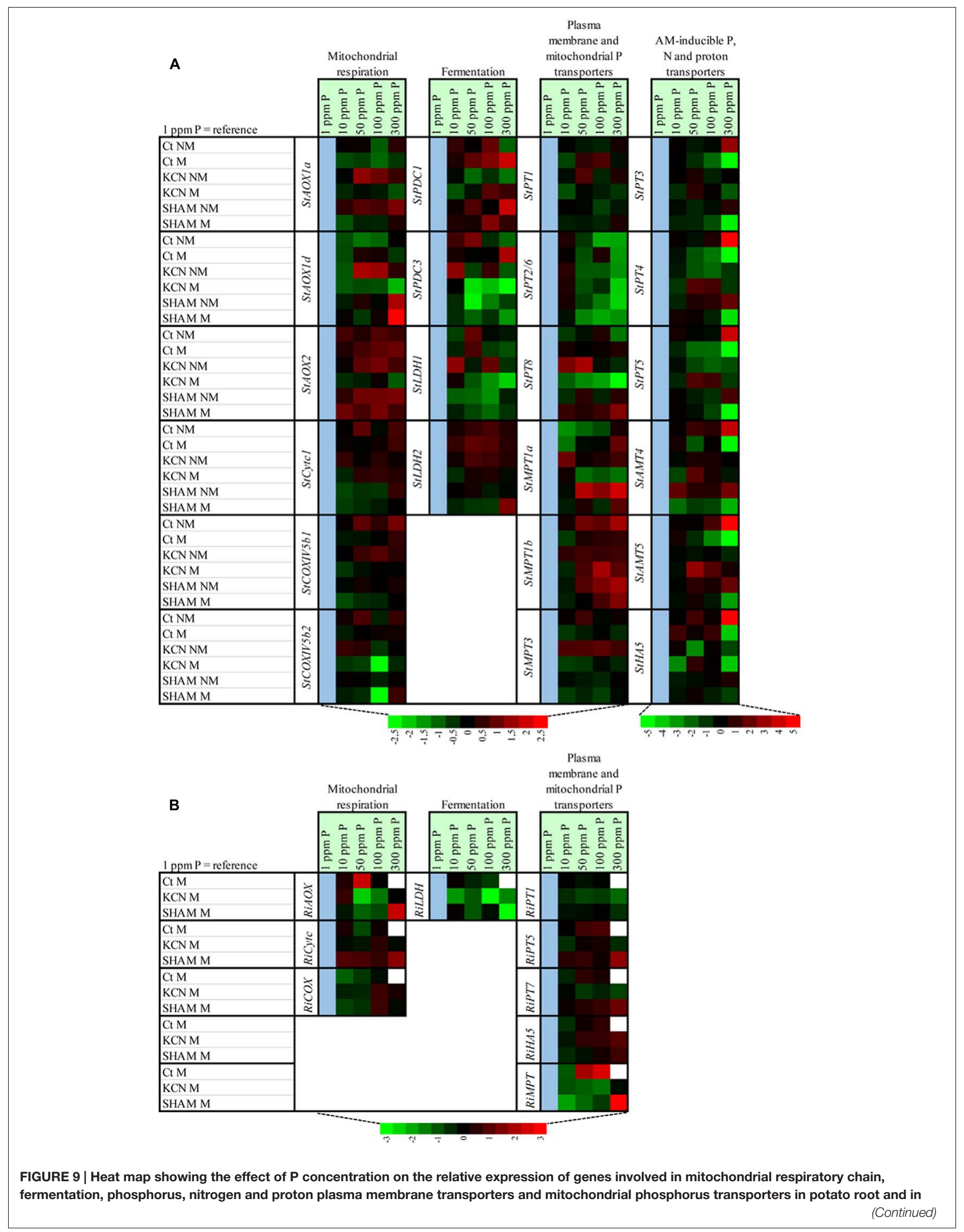




\section{FIGURE 9 | Continued}

R. irregulare, following inoculation or not of AMF, treatment or not with two respiratory inhibitors through two phosphorus concentrations. The heat map shows the real-time quantitative RT-PCR (qRT-PCR) analysis results of genes involved in mitochondrial respiratory chain (three StAOX isoforms, StCytc1, StCOXVb1, StCOXVb2, RiAOX, RiCytc, and RiCOXIVb), fermentation (two StPDC and two StLDH isoforms and RiLDH), phosphorus, nitrogen and proton plasma membrane transporters (six StPT isoforms, two StAMT isoforms, StHA1, three RiPT isoforms and RiHA5) and mitochondrial phosphorus transporters (three StMPT isoforms and RiMPT) in potato root (A) and in R. irregulare (B), under five phosphorus concentrations and following treatment by $\mathrm{KCN}$ (at $7 \mathrm{DAl}-0.1 \mathrm{mM}$ ) or SHAM (at $7 \mathrm{DAl}-0.1 \mathrm{mM}$ ) or not treated $(C t)$. Plants were inoculated $(\mathrm{M})$ or not $(\mathrm{NM})$ by $R$. irregulare. The expression levels of genes are presented using fold-change values transformed to Log2 format compared to $1 \mathrm{ppm} \mathrm{P}$ as reference (cell in blue). White cells correspond to non-determined analyses. The Log2 (fold-change values) and the color scale are shown at the bottom of heat map.

interplay during spore germination in $R$. irregulare as spores can return into dormancy and germinate again several times without obvious phenotypic signs (Giovanetti et al., 2010), and the hyphal tube germination is the physiological consequence of an already implemented respiratory shift, as shown for Mucor rouxii (Cano-Canchola et al., 1988).

Nevertheless, our data (Experiment 1) with KCN suggest that AOX is very likely involved in spore dormancy. Application of SHAM or KCN inhibited the spore germination, supporting the importance of both electron pathways and a possible involvement of a respiratory shift from AOX to COX. However, further work is needed to confirm this statement. AMF spores are sensitive to plant hormones, and their germination responses harbor opposite patterns between the antagonistic hormones ABA and $\mathrm{Ga} 3$, as ABA maintained spore dormancy while Ga3 broke it, similarly to plant seeds (White and Rivin, 2000; Linkies and Leubner-Metzger, 2012). Therefore, these observations support the need to apply ABA as pre-treatment (Experiment 2) and the need to apply the respiratory inhibitors some days after plant inoculation (Experiment 3) in order to not disturb the presymbiotic developmental phase of $R$. irregulare. Promotion of hyphal branching pattern in ABA treatment fits with previous observations: Juge et al. $(2002,2009)$ showed that spores develop g-type pattern germination (fine branching hyphae) around spores when dormancy is incompletely broken or under stress conditions, while G-type pattern (runner hyphal growth pattern) occurs in favorable conditions. Hyphal branching from germ tube generated by ABA seems similar to its effect on the arbuscule formation (Herrera-Medina et al., 2007).

As a remark, INT staining data suggested a low spore viability in Ga3 and SHAM treatment and higher after ABA and KCN (5 mM) treatment. However, no formazan production was observed in germinated spores following Ga3 application, while the germinative hypha was still growing (data not shown). This suggests that INT staining could correspond to a reducing power marker in the cell, and might be associated to AOX metabolism and spore dormancy, rather than solely to a vital staining.

\section{Mitochondrial Respiratory Inhibitors Influence Fungal Behavior at Symbiotic Phase}

Occurrence of the Arum- and Paris-types are not well understood and corresponds to extremes, which can coexist in a developmental continuum within the same root structure (Smith and Read, 2008). Their formation depends partly on genotypic factors characterizing both partners (Karandashov et al., 2004), partly on environmental factors like phosphate availability (Smith and Read, 2008). In potato roots, both mycorrhizal types and root colonization are commonly influenced by phosphate concentration (McArthur and Knowles, 1992). This is in agreement with our observations since $P$ concentration inhibited mycorrhizal development in a dosedependent way, and Arum-type structures were occurring at low to medium $\mathrm{P}$ concentration $(1,10$, and $50 \mathrm{ppm})$, while Paris-type formation appeared at higher $\mathrm{P}$ levels (100 and $300 \mathrm{ppm})$.

Our data on mycorrhized potato suggest that AOX or AOX-related metabolism is involved in arbuscule/hyphal branching and Arum-type formation, while COX or COXrelated metabolism is associated with higher hyphal growth and hyphal-coiled shape (Paris-type) formation. Despite the use of SHAM being controversial because of its possible non-specificity to AOX (Bingham and Stevenson, 1995; Day et al., 1996), our results showed differential and opposite phenotypic patterns in plant and fungal behavior when SHAM and KCN treatments were compared. $\mathrm{KCN}$ and $\mathrm{ABA}$ are known to stimulate AOX activity (Finkelstein et al., 1998; Choi et al., 2000; Rook et al., 2006; Giraud et al., 2009; Millar et al., 2011; Lynch et al., 2012; Wind et al., 2012). These two molecules promoted both arbuscule intensity and branching, but they caused differential mycorrhizal development ( $\mathrm{M} \%$ ), with ABA treated plants yielding a higher $\mathrm{M} \%$ (with colonization in the primary adventitious root recognized under the experimental conditions even up to the base stem). This could be explained by the fact that COX capacity is not inhibited by ABA unlike KCN. On the other hand, we observed that ABA (Experiment 2) tended to promote the AOX gene transcript levels in non-inoculated potato plantlets, but such response was not clearly identified when using $\mathrm{KCN}$ (Experiment 3). It would therefore suggest that the mycorrhizal root colonization, but also transcript regulation of the AOX pathway, are dependent from the functional state on the COX pathway. To summarize, we can deduce that mycorrhizal behavior seems to be linked to the mitochondrial respiratory chain-partitioning environment, probably generated from both partners. As a remark, ethylene is another stress hormone that is able to induce AOX pathway (Simons et al., 1999; Wang et al., 2010; Xu F. et al., 2012), but usually impairs mycorrhizal colonization (using epinastic plant or exogenous application, Zsögön et al., 2008; Fracetto et al., 2013). This phenomenon could be partly explained by the action of cyanide (HCN) produced stoichiometrically (1:1) with ethylene, blocking therefore the COX pathway (Xu F. et al., 2012). 


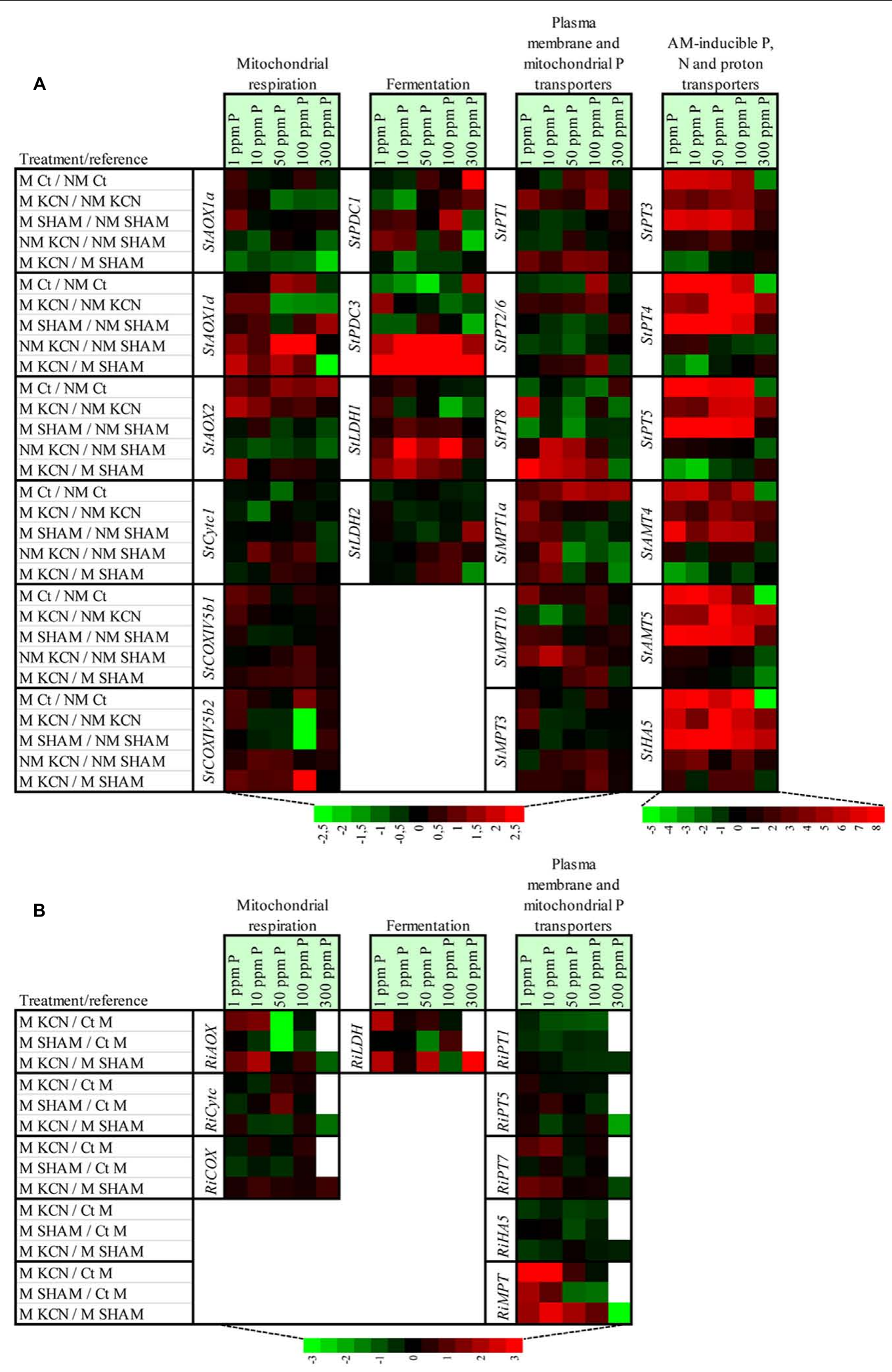

FIGURE 10 | Heat map showing the effect of treatments on the relative expression of genes involved in mitochondrial respiratory chain, fermentation, phosphorus, nitrogen and proton plasma membrane transporters and mitochondrial phosphorus transporters in potato root and in 


\section{FIGURE $10 \mid$ Continued}

R. irregulare, following inoculation or not of AMF, treatment or not with two respiratory inhibitors through five phosphorus concentrations. The heat map shows the real-time quantitative RT-PCR (qRT-PCR) analysis results of genes involved in mitochondrial respiratory chain (three StAOX isoforms, StCytc1, StCOXVb1, StCOXVb2, RiAOX, RiCytc and RiCOXIVb), fermentation (two StPDC and two StLDH isoforms and RiLDH), phosphorus, nitrogen and proton plasma membrane transporters (six StPT isoforms, two StAMT isoforms, StHA1, three RiPT isoforms and RiHA5) and mitochondrial phosphorus transporters (three StMPT isoforms and RiMPT) in potato root (A) and in R. irregulare (B), under five phosphorus concentrations and following treatment by KCN (at 7 DAl - 0.1 mM) or SHAM (at $7 \mathrm{DAl}-0.1 \mathrm{mM}$ ), or not treated $(C t)$. Plants were inoculated $(\mathrm{M})$ or not $(\mathrm{NM})$ by $R$. irregulare. The expression levels of genes are presented using fold-change values transformed to Log2 format compared to mentioned treatment in the table. White cells correspond to non-determined analyses. The Log2 (fold-change values) and the color scale are shown at the bottom of heat map.

Interpretation of the sporulation rise at $50 \mathrm{ppm} \mathrm{P}$ in $\mathrm{M}$ plants is challenging, but it seems linked with specific plant metabolism independent of mycorrhizal colonization ( $\mathrm{M} \%)$, as already observed by past studies (Douds and Schenck, 1990), while this last parameter harbored high correlation with $\mathrm{P}$ concentration. A particularity is observed at $50 \mathrm{ppm} \mathrm{P}$ concentration through the various plant phenotypical parameters studied (plant growth parameters - Supplementary Figure S2; mycorrhizal dependency - Figure 8) and corresponds to the highest value of arbuscule intensity (a \%, Supplementary Figure S1) with a predominant Arum-type, concomitant with an up-regulation of RiAOX transcripts (Figure 9) and the highest sporulation (Figure 5).

Taking into account all these observations, we propose a scheme defining the roles of AOX and COX in the different mycorrhizal phenotypical behaviors (Figure 11).

\section{Mitochondrial Respiratory Inhibitors Induced Opposite Mycorrhizal Growth Dependency}

Although many factors can influence the MGD, it is usually recognized that high $\mathrm{P}$ concentrations decrease MGD, which may become negative (Smith and Smith, 2011a). In our study, no correlation was found between MGD and P concentration, but respiratory inhibitors induced opposite responses. All possible MGD responses (neutral for non-treated plants, positive under KCN and negative under SHAM) were observed within the same AMF-plant biosystem, illustrating the high plasticity of mycorrhizal behavior linked to the physiological context. We show the possibility to obtain increasing yield with increasing $\mathrm{P}$ concentration when respiration in the plant-AMF system is associated with $\mathrm{AOX}$ pathway (i.e., in $\mathrm{KCN}$ treatments), occurring with a low fungal colonization and associated with relatively stable and almost maximal positive MGD. This goes together with a predominant Arum-type structures and higher arbuscule intensity when compared to treatments where COX pathway would be engaged (i.e., in SHAM treatments), in which Paris-type structure is predominant and associated with a negative MGD. This is consistent with the study of van Aarle et al. (2005), showing that Arum-type structures had higher metabolic activity than Paris-type ones. Moreover, even if SHAM reduced the MGD and the arbuscule intensity, while favoring Paris-type structures, the AMF produced a denser mycelium (h \%) and as many vesicles as in non-treated mycorrhizal plants (except at $1 \mathrm{ppm}$ P). AMF responses on plant performance seem therefore to depend mainly on the ability to form hyphal branching
(Arum-type), possibly by an increased exchange surface for providing nutrients to plants (Kobae and Hata, 2010; Bapaume and Reinhardt, 2012). However, if MGD responses seem related with arbuscule type in KCN and SHAM treatments, no direct relationship was found between arbuscule intensity and MGD. This leads to the hypothesis that although various membrane transporters (phosphate, amino acid, sugar or nitrogen) were characterized in arbuscules, these fungal structures might not constitute preferential sites for nutrient/element exchanges, and a role should be also attributed to intraradical hypha. This assumption is supported by the fact that glucose transporters were observed not only in arbuscules but also on intraradical hyphae (Helber et al., 2011).

The mycorrhizal dependency variation has been attributed to plant species and cultivars, fungal species and isolates, host and symbiont interplay, mycorrhizal rate, soil phosphorus concentration and environmental conditions (Plenchette et al., 1983; Singh, 2001; Smith and Smith, 2011a). Our data suggest that the electron flow partitioning, which is modulated by environmental stimuli and genetic background, corresponds to a main metabolic component determining the MGD related to the mycorrhizal type. Finally, AOX metabolism, linked usually with higher ABA content, is known to be related to plant growth regulation and has been reported to be connected to growth depression (Sieger et al., 2005). This may partly explain the negative MGD phenomenon that AMF might trigger during early developmental stages in some plant species (Koide, 1985; Graham and Abbott, 2000; Smith et al., 2009; Ronsheim, 2012) during the implementation of the induced systemic response in the plant (Pozo et al., 2002; Hause and Fester, 2005; Hause et al., 2007).

\section{Mitochondrial Respiratory Inhibitors Influence Symbiotic Nutrient Transport}

Arbuscular mycorrhizal inducible $\mathrm{Pi}$ transporters of the Pht1 family have been described as markers of mycorrhizal development and, in some cases, proposed as markers of mycorrhizal functionality (Javot et al., 2007). Partly in accordance to this statement, our data show a correlation between AMinducible transporter expression (StPT3, StPT4, and StPT5) and the mycorrhizal development. A gradual repression of the MPU pathway with increasing $\mathrm{P}$ availability in non-treated mycorrhizal plants was also observed, which is in accordance with several previous studies on Solanaceae species (Chen et al., 2007; Nagy et al., 2009), suggesting that the MPU is not functional at high $\mathrm{P}$ levels. However, the repression of the 


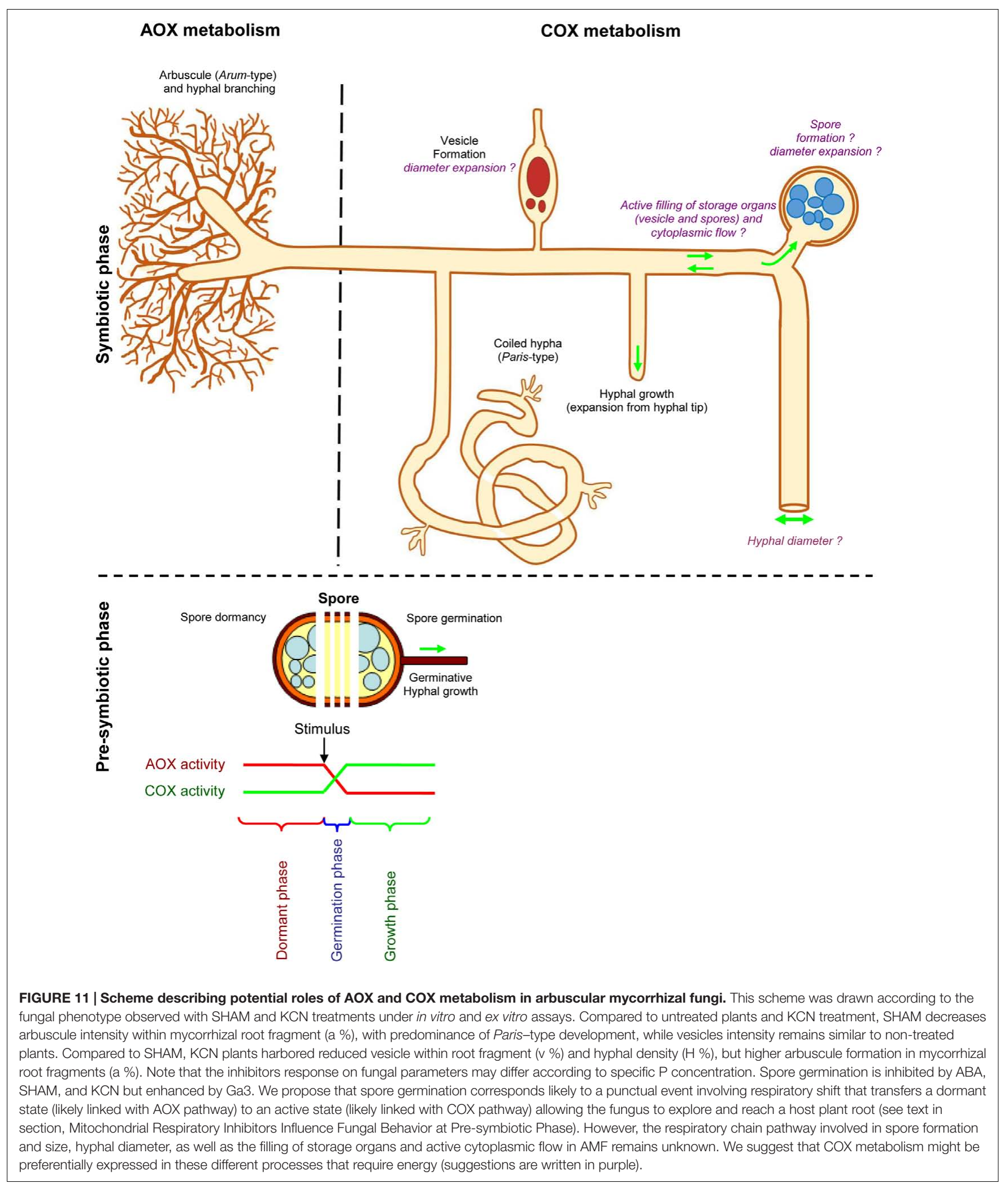

MPU by P disappeared when plants were treated with KCN, and surprisingly all AM-inducible P transporters were strongly up-regulated at $300 \mathrm{ppm}$ in non-inoculated plants. This last observation deserves further investigations, as no previous works have been done with very high $\mathrm{P}$ concentrations to our knowledge. 
The mycorrhizal impact on DPU is less clear. A number of studies have shown that AM colonization of plants downregulates the expression of the DPU Pi transporters (Rausch et al., 2001; Burleigh et al., 2002; Glassop et al., 2005; Requena, 2005; Nagy et al., 2006), while other studies pointed contrasted transcriptional regulations. Chen et al. (2007) showed a mycorrhiza-induced down-regulation of Pht1;1 and Pht1;2 expression under low-P conditions, but up-regulation of Pht1;2 under high-P conditions for pepper, eggplant and tobacco. In tomato, Nagy et al. (2009) did not find any change in the transcript abundance for SlPT1 and SIPT2 upon root colonization. Our data are in accordance with these latter observations, as presence of AMF did not necessarily induced down-regulation of non-AM-inducible transporters, but responses were specific to $\mathrm{P}$ concentrations. For example, it was noticed that AMF induced an up-regulation at $100 \mathrm{ppm} P$ but a down regulation at $10 \mathrm{ppm} P$ for $S t P T 1$, while an up-regulation of $S t P T 2 / 6$ was observed at $100 \mathrm{ppm}$ P. Only StPT2/6 was regulated by $\mathrm{P}$ availability. KCN treatment induced an up-regulation of DPU transporters in mycorrhizal conditions.

Fungal Pht1 genes are known to be expressed in the intraradical phase (Harrison and van Buuren, 1995; Benedetto et al., 2005; Balestrini et al., 2007; Tisserant et al., 2012; Fiorilli et al., 2013; Walder et al., 2016). Fiorilli et al. (2013) showed a slight down-regulation of RiPT1 when exposed to higher P concentrations, and Walder et al. (2016) reported a positive correlation of RiPT5 transcript levels and Pi acquisition in Sorghum. In our study, only RiPT5 was slightly regulated by P levels, with up-regulation in concentrations higher than $50 \mathrm{ppm}$ in non-treated conditions. Few data exist on the translocation of Pi across the inner mitochondrial membrane by Pht3 family in plants and fungi. In our study, no clear role emerged for these transporters within AMF symbiosis. StMPT3, which presented the highest expression levels in the roots, appeared to be constitutive, and only StMPT1a was slightly up-regulated by the presence of $R$. irregulare in non-treated conditions. RiMPT appeared also to be constitutively expressed in our experimental conditions.

In plants, several transcriptomic analyses revealed that AM establishment can induce the expression of plant $\mathrm{N}$ transporters, mainly in arbusculated cells (Gomez et al., 2009; Guether et al., 2009; Kobae et al., 2010; Gaude et al., 2012; Ruzicka et al., 2012). AMTs identified in tomato LeAMT4 and LeAMT5 were reported to be exclusively expressed in mycorrhizal roots and not regulated by $\mathrm{NH}_{4}{ }^{+}$(Ruzicka et al., 2012). The two potato homologs, StAMT4 and StAMT5, were strongly up-regulated by AMF, and were gradually repressed by $\mathrm{P}$ in mycorrhizal plants. This decrease in transcript levels can be attributed to the reduction of fungal structures inside the roots. However, in the case of AM-inducible AMTs, such as AM-inducible Pht1, NM plants presented a strong up-regulation at a high $P$ level $(300 \mathrm{ppm})$. As for $\mathrm{P}$ transporters, a suppression of this upregulation at $300 \mathrm{ppm} \mathrm{P}$ in the presence of $\mathrm{KCN}$ was observed and could be explained by the need of a functional COX pathway for ammonium and phosphate transport. $\mathrm{NH}_{4}{ }^{+}$uptake via AMT seems indeed to be accompanied by $\mathrm{H}^{+}$extrusion by the plasma membrane $\mathrm{H}^{+}$-ATPases for maintenance of the cytosolic charge balance, and increased fluxes of $\mathrm{NH}_{4}{ }^{+}$would increase the demand for respiratory ATP (Britto and Kronzucker, 2005). Hachiya et al. (2010) suggested that the ammonium-dependent increase of the $\mathrm{O}_{2}$ uptake rate can be explained by the upregulation of the cytochrome pathway, which may be related to the ATP consumption by the plasma-membrane $\mathrm{H}^{+}$-ATPases. Similarly, P transport is a proton-dependent process, and the $\mathrm{H}^{+}$-ATPase HA1 of Medicago truncatula was shown as essential for P transport in AM symbiosis (Krajinski et al., 2014). StHA1 is also up-regulated at $300 \mathrm{ppm} \mathrm{P}$ in non-inoculated plants compared to $1 \mathrm{ppm} \mathrm{P}$ and repressed in mycorrhizal plants. It can be therefore hypothesized that an impaired COX pathway would repress ammonium transport via AMT gene family members.

$\mathrm{P}$ and $\mathrm{N}$ AM-inducible transporters were found to be connected to the mycorrhizal development in non-treated plants. On the other hand, no correlation was observed between the expression of $\mathrm{P}$ and $\mathrm{N}$ AM-inducible transporters and the presence of either specific fungal structures (arbuscule or intraradical hypha) or any MGD parameters across the treatments (Supplementary Tables S2-S4). In particular, M KCN plants were associated with positive MGD compared to NM KCN plants but the transcript levels of genes encoding AMinducible transporters were similar to M SHAM treatments. Several studies showed a lack of relationship between Pht1 gene expression and mycorrhizal Pi acquisition (Grace et al., 2009; Grønlund et al., 2013; Walder et al., 2015). It would therefore indicate that MGD and that plant's Pi acquisition through the MPU is not quantitatively regulated by the expression level of AM-inducible Pht1 genes. These observations, combined with the lack of repression of the MPU by $\mathrm{P}$ in presence of $\mathrm{KCN}$, and the strong up-regulation of AM-inducible $\mathrm{P}$ transporter genes at $300 \mathrm{ppm}$ in NMs, suggest that these transporters are not suitable markers for a functional symbiosis in field conditions where high $P$ concentrations can occur and natural or anthropogenic source of cyanides can be found in soil or water (with concentrations as high as $100 \mathrm{mg} \mathrm{kg} \mathrm{DW}^{-1}$ ).

\section{What about the Metabolic Role of AOX and COX in AMF?}

Despite sugar transporters being found and characterized (Helber et al., 2011), AMF are still unable to complete their life cycle even when carbon sources are added in in vitro culture systems without the presence of plant roots. Some publications showed even the opposite: glucose and fructose application under axenic or monoxenic conditions resulted in reduced fungal growth or spore germination rate (Mosse, 1959; Koske, 1981; Hepper, 1982; Siquiera and Hubbell, 1986; Wang et al., 2015), while culture media devoid of sucrose can stimulate spore germination, hyphal growth (D'Souza et al., 2013), as well as, sporulation (St-Arnaud et al., 1996). In many publications, the definition of obligate biotrophy of AMF deals with their dependency on plants for carbohydrate supply (mainly glucose and fructose, Pfeffer et al., 1999). But obviously, this statement seems incomplete since it is not yet strictly proven by the successful implementation of an axenic culture. Genomic and transcriptomic data obtained from $R$. irregulare were not helpful since this fungal species 
would possess all the necessary genes to harbor saprobe behavior (Tisserant et al., 2012; Tisserant et al., 2013), although no evidence for gene encoding for fungal multi-domain fatty acid synthase was found (Wewer et al., 2014). Therefore, the fungal needs related to the biotrophy of AMF remains still an open question. In this way, it seems important to emphasize that plants provide, at least, a habitat, i.e., a physical growth support associated with a favorable physiological frame allowing uptake and metabolic assimilation of carbon sources that AMF seems not to encounter without host. This questions the definition of the metabolic frame (induced by stress signals) favorable to AMF colonization, arbuscule development and functions on plant performances. We discuss below the role of COX and AOX, which can shed new light that would allow a better understanding and mastering of mycorrhiza.

\section{COX Pathway and Aerobic Respiration}

In non-inoculated plants, fresh biomass and potato yield are repressed by KCN and enhanced by SHAM (especially at 100 and $300 \mathrm{ppm} \mathrm{P}$ ). This suggests that the tuberization is an active COX-dependent process needing $\mathrm{O}_{2}$, which is consistent with the high $\mathrm{O}_{2}$ concentration requirement observed previously for tuber formation (Saini, 1976; Hooker, 1981; Cary, 1985; Geigenberger et al., 2000). This fits also with the reported effect of SHAM, known to optimize the $\mathrm{O}_{2}$ flow through plant tissues (Sesay et al., 1986; Spreen Brouwer et al., 1986; Møller et al., 1988; Gupta et al., 2009). The positive MGD on yield observed in KCN treatment suggests that AMF improve plant respiration, not only related to $\mathrm{P}$ concentration, but also to tissue oxygenation, in order to sustain both COX needs and a better carbon allocation in the tuber. However, our expression data obtained at harvest for StCOXVb and StCytc1 genes are difficult to interpret in link with these assertions. StCytc1 expression is up-regulated in NM KCN plants compared to NM SHAM plants at 10 and $100 \mathrm{ppm} \mathrm{P,} \mathrm{but} \mathrm{it}$ remains similar for the other $\mathrm{P}$ concentrations tested, suggesting probable other regulation levels related to COX pathway.

Potassium cyanide impacted negatively intraradical hyphal growth and vesicle formation, likely by blocking $\mathrm{O}_{2}$ consumption needed for fungal COX metabolism. It is known that anaerobic conditions in flooded soils is associated with reduced mycorrhizal colonization (Miller and Sharitz, 2000). Moreover, arbuscules are resistant to $\mathrm{KCN}$ when compared to non-treated plants, but their intensity is promoted compared to SHAM in all $\mathrm{P}$ concentrations, increasing, therefore, the arbuscule/intraradical hypha ratio. This is consistent with the results of Saif (1981), where soil $\mathrm{O}_{2}$ content was correlated with the mycorrhizal development and vesicles production, and arbuscule occurrence was observed only at specific $\mathrm{O}_{2}$ concentration but not under soil $\mathrm{O}_{2}$ excess. Depression of arbuscule intensity by SHAM might be related to a higher $\mathrm{O}_{2}$ availability for AMF respiration in roots. The sensitivity of arbuscules to $\mathrm{O}_{2}$ raises the possibility that they might be a respiration structure where gas exchanges between both partners might occur. Soils have usually less available $\mathrm{O}_{2}$ (Clark, 1967; Bhattarai et al., 2005) and are enriched in $\mathrm{CO}_{2}$ compared to ambient atmosphere (Bouma and Bryla, 2000; Pfanz et al., 2004). As Miller and Bever (1999) suggested, $\mathrm{O}_{2}$ could be provided by the plant and mobilized for COX-metabolism needs for fungal growth. The increase of mycorrhizal development in $\mathrm{ABA}$ treated plants could be linked to a promoted plant COX pathway potential, this hypothesis being supported by the induction of StCytc1 gene in $\mathrm{M}+\mathrm{ABA}$ treatment.

\section{AOX Pathway and Fermentation}

Our data showed that AOX is involved in specific plant and fungal behavior. However, its energetic metabolic significance is not yet well understood. In order to better interpret its functions within mycorrhizal symbiosis, we thought it was relevant to enlighten possible connections with fermentation, as one "AOXrelated key metabolism.”

Fermentation pathways use pyruvate as source that can be reduced to lactate (by $\mathrm{LDH}$ ) in presence of reducing potential (NADH) or processed into $\mathrm{CO}_{2}$ and acetaldehyde (by PDC, a thiamine pyrophosphate-dependent enzyme), which is then reduced into ethanol (alcohol dehydrogenase) or acetate (aldehyde dehydrogenase), also in presence of NADH. Pyruvate can be synthesized from glucose (classic glycolytic pathway) or from malate (alternative glycolytic pathway) depending on the pH-stat and therefore redox potential (Sakano, 2001). Several clues from previous metabolic studies suggest a possible link between AOX and fermentation in plants but also in fungi and are detailed in Supplementary Material (Section 3).

In our study, $\mathrm{P}$ concentration was not directly correlated with fermentation in non-treated conditions. But we noticed in Experiment 3 an induction of StLDH1 and StPDC3 occurring at several $\mathrm{P}$ concentrations, when comparing KCN to SHAM treatments. Moreover, our data from the ABA test showed that expression of genes involved in fermentation in noninoculated plants were associated with the higher expression of the genes encoding for AOX isoforms and lower StCytc1. These observations would indicate persistent implementation of the fermentative system under stressed conditions, which was expected in these situations.

From our data, the sporulation pattern in non-treated plants was not correlated with mycorrhizal colonization, while this last parameter harbored high correlation with $\mathrm{P}$ concentration. This could suggest that spore formation and mycorrhizal development, requiring obviously energy for their development, may need the involvement of at least two carbon source partitioning. We noticed a significant correlation between sporulation and the StLDH1 profile, both showing, with the RiAOX transcripts, maximum values at $50 \mathrm{ppm} P$ (non-treated plants). At the same time, the presence of AMF reduced significantly the total biomass only at $50 \mathrm{ppm} \mathrm{P}$ without disturbing the potato yield biomass indicating influence of a specific stress. This assumption is supported by a downregulation of $S t C y t c 1$ but an up-regulation of StAOX2 (comparing $\mathrm{M} / \mathrm{NM}$ plants in Experiment 3). Then, ABA data suggest that a higher mycorrhizal colonization is the consequence of an initial physiological stress state implemented in plant prior to root contact by AMF, in which AOX and fermentation seems to take place.

This connection between AOX-metabolism and fermentation leads to the hypothesis that AMF might partly stimulate plants to provide - or generate a metabolic environment that favors 
the fungal synthesis of - fermentation products as possible carbon sources for its storage needs. This assumption seems, to our knowledge, underestimated since no publication discusses directly these aspects on AMF, although it is known that presence of fermentative organisms/fermented products in soil can stimulate mycorrhizal development (Medina et al., 2007, 2010; Azcón et al., 2013), providing a clue. In particular, our data suggest that lactate, as one energy source for fungal needs, seems to be a good candidate, involved perhaps in sporulation potentials and arbuscule formation. Attempting to give a little more insight, first tests using exogenous lactate on potato plants under greenhouse conditions showed that it was possible to increase significantly the mycorrhizal colonization and arbuscule intensity associated with a positive MGD (Mercy, personal observation). As a remark, attention should be paid in further works to the role of the alternative glycolytic pathway (NAD/NADP malic enzymes) in mycorrhizal behavior, as it involves malate as source for fermentation and AOX pathway, both engaged during P-deficiency, a stress condition usually favoring the mycorrhizal development.

\section{Open Questions and Perspectives}

This is the first work that extensively studies phenotypic patterns by using respiratory chain inhibitors in mycorrhizal symbiotic associations. Plant growth parameters suggest that "AOX plants" (plants that are able to engage AOX pathway to a higher extent) are more positively responsive to AMF and have higher potentials in carbon allocation to the potato tuber than "COX plants" (plants that show a higher engagement of COX pathway), and plants treated with $\mathrm{ABA}$ or with $\mathrm{KCN}$ indicated that AMF inoculation is efficient to counteract extreme stresses in terms of growth performance. Under stress-related physiology, AOX might represent the main (or a more engaged) respiratory chain pathway in plant roots, concomitant with higher fermentation that might favor arbuscule development. In analogy to previous observations (Liu et al., 2015), we observed that the presence of AMF reduces plant stress and seems to favor the COX pathway, which is consistent with higher energetic metabolism that associates to positive MGD. Therefore, artificial soft and transitory induction techniques of AOX metabolism in plants, without disturbing COX potential, could represent a physiological target for producers for improving mycorrhizal plant susceptibility and mycorrhizal dependency.

It is very likely that the modulation of respiration partitioning occurs at different stages of AMF life cycle, as shown during presymbiotic phase by the induction of mitochondrial respiration by several plant root exudates (Tamasloukht et al., 2003; Besserer et al., 2008) and AOX expression along the symbiotic establishment (Campos et al., 2015). Optimal mycorrhizal development needs obviously oxygen (KCN data) but seems also related to fermentation (ABA data). This opens the possibility that AMF, at a whole, might belong to obligate aerobic fermentative organisms. Therefore, the role of fermentation in mycorrhizal behavior deserves further investigations providing potentially exciting new avenues for next studies.
While the application of respiratory inhibitors induced significant changes from phenotypical parameters and the expression of some genes involved in transport and fermentation, interpretation of transcriptomic data related to AOX and COX pathways was challenging. However, respiration genes are hierarchically superimposed to specific metabolic pathway genes. Increasing data supports the hypothesis that the most crucial responses of AOX genes to changing environments are induced early during cell reprogramming before specific pathways are initiated and interfere with growth performance (Arnholdt-Schmitt et al., 2006). Recently, this was confirmed for the carrot anti-freezing protein gene under cold treatment (Campos et al., 2016). Furthermore, in A. thaliana, it was shown that limitation of the capacity of the alternative-, cytochrome-, or both termini-oxidases results in unique and overlapping transcriptional responses depending on growth conditions. Nevertheless, this research presented the first clues for the implication of respiratory metabolism in a mycorrhizal symbiosis seen as a holobiont level system. Thus, our research supports further deeper molecular-physiological studies on respiration traits and exploiting genetic approaches through overexpressing and knock-out or respiratory gene editing techniques. However, final progress in order to associate complex respiration metabolism to robust growth performance will absolutely depend also on the development of adequate predictive and phenotyping-screening technologies (Fiorani and Schurr, 2013; Arnholdt-Schmitt et al., 2014, 2016; Nogales et al., 2016).

\section{AUTHOR CONTRIBUTIONS}

LM and EL-M conceptualized the experimental design and contributed equally to research, trial conductance and data interpretation. BA-S initiated research on the role of AOX on plant-AMF interaction, developed and coordinated together with CS the supporting IAPP research project (AGRO-AMF-AOX). AN contributed to data interpretations. AP was involved in the trial performance and contributed to data interpretations. LM and EL-M designed and wrote the manuscript and all the authors revised and approved it.

\section{FUNDING}

This work was supported by a Marie Curie project grant within the program Industry-Academia Partnerships and Pathways from the European Commission (IAPP: AGRO-AMFAOX, European Union's Seventh Framework Programme for research).

\section{ACKNOWLEDGMENTS}

The authors thank Bea Ceipek, Andrea Rathje and INOQ glasshouse team for help with trial implementation; Imke Hutter 
for her permanent availability for discussions; Hillary Cirka, Tânia Nobre, Carla Lopes, and Philipp Franken for insightful suggestions to improve the manuscript, and Luìs S. Dias for his assistance with statistical analysis.

\section{REFERENCES}

Andersen, C. L., Jensen, J. L., and Orntoft, T. F. (2004). Normalization of real-time quantitative reverse transcription-PCR data: a model-based variance estimation approach to identify genes suited for normalization, applied to bladder and colon cancer data sets. Cancer Res. 64, 5245-5250. doi: 10.1158/00085472.CAN-04-0496

Arnholdt-Schmitt, B., Costa, J. H., and Fernandes de Melo, D. (2006). AOX - a functional marker for efficient cell reprogramming under stress? Trends Plant Sci. 11, 281-287.

Arnholdt-Schmitt, B., Hansen, L. D., and Nogales, A. (2016). Calorespirometry, oxygen isotope analysis and functional-marker-assisted selection ('CalOxyFMAS') for genotype screening: a novel concept and tool kit for predicting stable plant growth performance and functional marker identification. Brief. Funct. Genomics 5, 10-15. doi: 10.1093/bfgp/elv008

Arnholdt-Schmitt, B., Valadas, V., and Doering, M. (2014). Functional marker development is challenged by the ubiquity of endophytes - a practical perspective. Brief. Funct. Genomics 15, 16-21. doi: 10.1093/bfgp/elu049

Aroca, R., Porcel, R., and Ruiz-Lozano, J. M. (2007). How does arbuscular mycorrhizal symbiosis regulate root hydraulic properties and plasma membrane aquaporins in Phaseolus vulgaris under drought, cold or salinity stresses? New Phytol. 173, 808-816. doi: 10.1111/j.1469-8137.2006.01961.x

Aroca, R., Ruiz-Lozano, J. M., Zamarreño, A. M., Paz, J. A., García-Mina, J. M., Pozo, M. J., et al. (2013). Arbuscular mycorrhizal symbiosis influences strigolactone production under salinity and alleviates salt stress in lettuce plants. J. Plant Physiol. 170, 47-55. doi: 10.1016/j.jplph.2012.08.020

Azcón, R., Medina, A., Aroca, R., and Ruiz-Lozano, J. M. (2013). "Abiotic stress remediation by the arbuscular mycorrhizal symbiosis and rhizosphere bacteria/yeast interactions," in Molecular Microbial Ecology of the Rhizosphere, 1st Edn, Vol. 2, ed. F. de Bruijn (Oxford: John Wiley \& Sons, Inc.), 991-1002.

Bago, B., Pfeffer, P. E., Abubaker, J., Jun, J., Allen, J. W., Brouillette, J., et al. (2003). Carbon export from arbuscular mycorrhizal roots involves the translocation of carbohydrate as well as lipid. Plant Physiol. 131, 1-11. doi: 10.1104/pp.102. 007765

Balestrini, R., Gomez-Ariza, J., Lanfranco, L., and Bonfante, P. (2007). Laser microdissection reveals that transcripts for five plant and one fungal phosphate transporter genes are contemporaneously present in arbusculated cells. Mol. Plant Microbe Interact. 20, 1055-1062. doi: 10.1094/MPMI-20-9-1055

Bapaume, L., and Reinhardt, D. (2012). How membranes shape plant symbioses: signaling and transport in nodulation and arbuscular mycorrhiza. Front. Plant Sci. 3:223. doi: 10.3389/fpls.2012.00223

Bedini, S., Pellegrino, E., Avio, L., Pellegrini, S., Bazzoffi, P., Argese, E., et al. (2009). Changes in soil aggregation and glomalin-related soil protein content as affected by the arbuscular mycorrhizal fungal species Glomus mosseae and Glomus intraradices. Soil Biol. Biochem. 41, 1491-1496. doi: 10.1016/j.soilbio. 2009.04.005

Benedetto, A., Magurno, F., Bonfante, P., and Lanfranco, L. (2005). Expression profiles of a phosphate transporter gene (GmosPT) from the endomycorrhizal fungus Glomus mosseae. Mycorrhiza 15, 620-627. doi: 10.1007/s00572-0050006-9

Berridge, M. V., Tan, A. S., and Herst, P. M. (2005). Tetrazolium dyes as tools in cell biology: new insights into their cellular reduction. Biotechnol. Annu. Rev. 11, 127-152. doi: 10.1016/S1387-2656(05)11004-7

Berruti, A., Lumini, E., Balestrini, R., and Bianciotto, V. (2016). Arbuscular mycorrhizal fungi as natural biofertilizers: let's benefit from past successes. Front. Microbiol. 6:1559. doi: 10.3389/fmicb.2015.01559

Besserer, A., Becard, G., Jauneau, A., Roux, C., and Séjalon-Delmas, N. (2008). GR24, a synthetic analog of strigolactones, stimulates the mitosis and growth of the arbuscular mycorrhizal fungus Gigaspora rosea by boosting its energy metabolism. Plant Physiol. 148, 402-413. doi: 10.1104/pp.108.121400

\section{SUPPLEMENTARY MATERIAL}

The Supplementary Material for this article can be found online at: http://journal.frontiersin.org/article/10.3389/fpls.2017.00417/ full\#supplementary-material

Besserer, A., Becard, G., Roux, C., and Sejalon-Delmas, N. (2009). Role of mitochondria in the response of arbuscular mycorrhizal fungi to strigolactones. Plant Signal. Behav. 4, 75-77. doi: 10.4161/psb.4.1.7419

Besserer, A., Puech-Pages, V., Kiefer, P., Gomez-Roldan, V., Jauneau, A., Roy, S., et al. (2006). Strigolactones stimulate arbuscular mycorrhizal fungi by activating mitochondria. PLoS Biol. 4:E226. doi: 10.1371/JOURNAL.PBIO

Bhattarai, S. P., Su, N., and Midmore, D. J. (2005). Oxygenation unlocks yield potentials of crops in oxygen limited soil environments. Adv. Agron. 88, 313-377. doi: 10.1016/S0065-2113(05)88008-3

Bingham, I. J., and Stevenson, E. A. (1995). Causes and location of non-specific effects of SHAM on O2 uptake by wheat roots. Physiol. Plant. 93, 427-434. doi: 10.1111/j.1399-3054.1995.tb06839.x

Bouma, T. J., and Bryla, D. R. (2000). On the assessment of root and soil respiration for soils of different textures: interactions with soil moisture contents and soil CO2 concentrations. Plant and Soil 227, 215-221. doi: 10.1023/A:1026502414977

Breuillin, F., Schramm, J., Hajirezaei, M., Ahkami, A., Favre, P., Druege, U., et al. (2010). Phosphate systemically inhibits development of arbuscular mycorrhiza in Petunia hybrida and represses genes involved in mycorrhizal functioning. Plant J. 64, 1002-1017. doi: 10.1111/j.1365-313X.2010.04385.x

Britto, D. T., and Kronzucker, H. J. (2005). Nitrogen acquisition, PEP carboxylase, and cellular $\mathrm{pH}$ homeostasis: new views on old paradigms. Plant Cell Environ. 28, 1396-1409. doi: 10.1111/j.1365-3040.2005.01372.x

Brundrett, M. C. (2002). Coevolution of roots and mycorrhizas of land plants. New Phytol. 154, 275-304. doi: 10.1046/j.1469-8137.2002.00397.x

Bucher, M. (2007). Functional biology of plant phosphate uptake at root and mycorrhiza interfaces. New Phytol. 173, 11-26. doi: 10.1111/j.1469-8137.2006. 01935.x

Burleigh, S. H., Cavagnaro, T., and Jakobsen, I. (2002). Functional diversity of arbuscular mycorrhizas extends to the expression of plant genes involved in $\mathrm{P}$ nutrition. J. Exp. Bot. 53, 1593-1601. doi: 10.1093/jxb/erf013

Campos, C., Cardoso, H., Nogales, A., Svensson, J., Lopez-Ráez, J. A., Pozo, M. J., et al. (2015). Intra and inter-spore variability in Rhizophagus irregularis AOX gene. PLoS ONE 10:e0142339. doi: 10.1371/journal.pone

Campos, M. D., Nogales, A., Cardoso, H. G., Rajeev Kumar, S., Nobre, T., Sathishkumar, R., et al. (2016). Stress-induced accumulation of DcAOX1 and DcAOX2a transcripts coincides with critical time point for structural biomass prediction in carrot primary cultures (Daucus carota L.). Front. Genet 7:1. doi: 10.3389/fgene.2016.00001

Cano-Canchola, C., Escamilla, E., and Ruiz-Herrera, J. (1988). Environmental control of the respiratory system in the dimorphic fungus Mucor rouxii. J. Gen. Microbiol. 134, 2993-3000. doi: 10.1099/00221287-134-11-2993

Cary, J. W. (1985). Potato tubers and soil aeration. Agron. J. 77, 379-383. doi: 10.2134/agronj1985.00021962007700030007x

Charest, C., Dalpé, Y., and Brown, A. (1993). The effect of vesicular arbuscular mycorrhizae and chilling on two hybrids of Zea mays L. Mycorrhiza 4, 89-92. doi: 10.1007/BF00204064

Chen, A., Chen, X., Wang, H., Liao, D., Gu, M., Qu, H., et al. (2014). Genomewide investigation and expression analysis suggest diverse roles and genetic redundancy of Pht1 family genes in response to Pi deficiency in tomato. BMC Plant Biol. 14:61. doi: 10.1186/1471-2229-14-61

Chen, A., Hu, J., Sun, S., and Xu, G. (2007). Conservation and divergence of both phosphate- and mycorrhiza-regulated physiological responses and expression patterns of phosphate transporters in solanaceous species. New Phytol. 173, 817-831. doi: 10.1111/j.1469-8137.2006.01962.x

Choi, H., Hong, J., Ha, J., Kang, J., and Kim, S. Y. (2000). ABFs, a family of ABA-responsive element binding factors. J. Biol. Chem. 275, 1723-1730. doi: 10.1074/jbc.275.3.1723

Clark, F. E. (1967). "Bacteria in soil," in Soil Biology, eds A. Burges and F. Raw (London: Academic Press), 15-49. 
Costa, J. H., McDonald, A. E., Arnholdt-Schmitt, B., and Fernandes de Melo, D. (2014). A classification scheme for alternative oxidases reveals the taxonomic distribution and evolutionary history of the enzyme in angiosperms. Mitochondrion 19, 172-183. doi: 10.1016/j.mito.2014.04.007

Day, D. A., Krab, K., Lambers, H., Moore, A. L., Siedow, J. N., Wagner, A. M., et al. (1996). The cyanide resistant oxidase: to inhibit or not to inhibit, that is the question. Plant Physiol. 110, 1-2. doi: 10.1104/pp.110.1.1

Douds, D. D., and Schenck, N. C. (1990). Relationship of colonization and sporulation by VA mycorrhizal fungi to plant nutrient and carbohydrate contents. New Phytol. 116, 621-627. doi: 10.1111/j.1469-8137.1990.tb00547.x

Draper, N. R., and Smith, H. (1998). Applied Regression Analysis, 3rd Edn. New York, NY: Wiley. doi: 10.1002/9781118625590

D’Souza, J., Rodrigues, K. M., and Rodrigues, B. F. (2013). Modified Strullu and Romand (MSR) medium devoid of sucrose promotes higher in vitro germination in Rhizophagus irregularis. J. Mycol. Plant Pathol. 43, 240-242.

Finkelstein, R. R., Wang, M. L., Lynch, T. J., Rao, S., and Goodman, H. M. (1998). The Arabidopsis abscisic acid response locus ABI4 encodes an APETALA 2 domain protein. Plant Cell 10, 1043-1054. doi: 10.1105/tpc.10. 6.1043

Fiorani, F., and Schurr, U. (2013). Future scenarios for plant phenotyping. Annu. Rev. Plant Biol. 64, 267-291. doi: 10.1146/annurev-arplant-050312-120137

Fiorilli, V., Lanfranco, L., and Bonfante, P. (2013). The expression of GintPT, the phosphate transporter of Rhizophagus irregularis, depends on the symbiotic status and phosphate availability. Planta 237, 1267-1277. doi: 10.1007/s00425013-1842-z

Fracetto, G. G. M., Peres, L. E. P., Mehdy, M. C., and Lambais, M. R. (2013). Tomato ethylene mutants exhibit differences in arbuscular mycorrhiza development and levels of plant defense-related transcripts. Symbiosis 60, 155-167. doi: 10.1007/s13199-013-0251-1

Gallaud, J. (1905). Etude sur les mycorrhizes endotrophes. Rev. Gén. Bot. 17, 5-48.

Gallou, A. (2011). Impact of Rhizophagus sp. (syn. Glomus sp.) and Trichoderma harzianum on the Potato Resistance Against Rhizoctonia solani and Phytophthora infestans, Two Major Potato Pathogens. Ph.D. thesis, Université catholique de Louvain, Louvain.

Gaude, N., Bortfeld, S., Duensing, N., Lohse, M., and Krajinski, F. (2012). Arbuscule-containing and non-colonized cortical cells of mycorrhizal roots undergo extensive and specific reprogramming during arbuscular mycorrhizal development. Plant J. 69, 510-528. doi: 10.1111/j.1365-313X.2011.04810.x

Geigenberger, P., Fernie, A. R., Gibon, Y., Christ, M., and Stitt, M. (2000). Metabolic activity decreases as an adaptive response to low internal oxygen in growing potato tubers. Biol. Chem. 381, 723-740. doi: 10.1515/BC.2000.093

Gerdemann, J. W., and Nicolson, T. H. (1963). Spores of mycorrhizal Endogone species extracted from soil by wet sieving and decanting. Trans. Br. Mycol. Soc. 46, 235-244. doi: 10.1016/S0007-1536(63)80079-0

Gianinazzi, S., Gollotte, A., Binet, M. N., van Tuinen, D., Redecker, D., and Wipf, D. (2010). Agroecology: the key role of arbuscular mycorrhizas in ecosystem services. Mycorrhiza 20, 519-530. doi: 10.1007/s00572-010-0333-3

Gianinazzi-Pearson, V., Gianinazzi, S., and Trouvelot, A. (1985). Evaluation of the infectivity and effectiveness of indigenous vesicular-arbuscular fungal populations in some agricultural soils in Burgundy. Can. J. Bot. 63, 1521-1524. doi: $10.1139 / \mathrm{b} 85-210$

Giovanetti, M., Avio, L., and Sbrana, C. (2010). "Fungal spore germination and presymbiotic mycelial growth - physiological and genetic aspects," in Arbuscular Mycorrhizas: Physiology and Function, eds H. Koltai and Y. Kapulnik (Berlin: Springer), 3-32.

Giraud, E., Van Aken, O., Ho, L. H., and Whelan, J. (2009). The transcription factor ABI4 is a regulator of mitochondrial retrograde expression of Alternative oxidase 1a. Plant Physiol. 150, 1-33. doi: 10.1104/pp.109.139782

Glassop, D., Smith, S. E., and Smith, F. W. (2005). Cereal phosphate transporters associated with the mycorrhizal pathway of phosphate uptake into roots. Planta 222, 688-698. doi: 10.1007/s00425-005-0015-0

Gomez, K. S., Javot, H., Deewatthanawong, P., Torres-Jerez, I., Tang, Y., Blancaflor, E. B., et al. (2009). Medicago truncatula and Glomus intraradices gene expression in cortical cells harboring arbuscules in the arbuscular mycorrhizal symbiosis. BMC Plant Biol. 9:10. doi: 10.1186/1471-2229-9-10

Grace, E. J., Cotsaftis, O., Tester, M., Smith, F. A., and Smith, S. E. (2009). Arbuscular mycorrhizal inhibition of growth in barley cannot be attributed to extent of colonization, fungal phosphorus uptake or effects on expression of plant phosphate transporter genes. New Phytol. 181, 938-949. doi: 10.1111/j. 1469-8137.2008.02720.x

Graham, J. H., and Abbott, L. K. (2000). Wheat responses to aggressive and nonaggressive arbuscular mycorrhizal fungi. Plant Soil 220, 207-218. doi: 10.1023/ A:1004709209009

Grahl, N., Dinamarco, T. M., Willger, S. D., Goldman, G. H., and Cramer, R. A. (2012). Aspergillus fumigatus mitochondrial electron transport chain mediates oxidative stress homeostasis, hypoxia responses and fungal pathogenesis. Mol. Microbiol. 84, 383-399. doi: 10.1111/j.1365-2958.2012. 08034.x

Grønlund, M., Albrechtsen, M., Johansen, I. E., Hammer, E. C., Nielsen, T. H., and Jakobsen, I. (2013). The interplay between P uptake pathways in mycorrhizal peas: a combined physiological and gene-silencing approach. Physiol. Plant. 149, 234-248. doi: 10.1111/ppl.12030

Guether, M., Neuhäuser, B., Balestrini, R., Dynowski, M., Ludewig, U., and Bonfante, P. (2009). A mycorrhizal-specific ammonium transporter from lotus japonicus acquires nitrogen released by Arbuscular Mycorrhizal Fungi. Plant Physiol. 150, 73-83. doi: 10.1104/pp.109.136390

Gupta, K. J., Zabalza, A., and van Dongen, J. T. (2009). Regulation of respiration when the oxygen availability changes. Physiol. Plant. 137, 383-391. doi: 10.1111/ j.1399-3054.2009.01253.x

Hachiya, T., Watanabe, C. K., Boom, C., Tholen, D., Takahara, K., KawaiYamada, M., et al. (2010). Ammonium-dependent respiratory increase is dependent on the cytochrome pathway in Arabidopsis thaliana shoots. Plant Cell Environ. 33, 1888-1897. doi: 10.1111/j.1365-3040.2010. 02189.x

Harrison, M. J., and van Buuren, M. L. (1995). A phosphate transporter from the mycorrhizal fungus Glomus versiforme. Nature 378, 626-629. doi: 10.1038/ $378626 \mathrm{a} 0$

Hause, B., and Fester, T. (2005). Molecular and cell biology of arbuscular mycorrhizal symbiosis. Planta 221, 184-196. doi: 10.1007/s00425-004-1436-x

Hause, B., Mrosk, C., Isayenkov, S., and Strack, D. (2007). Jasmonates in arbuscular mycorrhizal interactions. Phytochemistry 68, 101-110. doi: 10.1016/ j.phytochem.2006.09.025

Helber, N., Wippel, K., Sauer, N., Schaarschmidt, S., Hause, B., and Requena, N. (2011). A versatile monosaccharide transporter that operates in the arbuscular mycorrhizal fungus Glomus sp is crucial for the symbiotic relationship with plants. Plant Cell 23, 3812-3823. doi: 10.1105/tpc.111. 089813

Hepper, C. (1982). Limited independant growth of a vesicular-arbuscular mycorhizal fungus in vitro. New Phytol. 93, 537-542. doi: 10.1111/j.1469-8137. 1983.tb02704.x

Herrera-Medina, M. J., Steinkellner, S., Vierheilig, H., Ocampo Bote, J. A., and García Garrido, J. M. (2007). Abscisic acid determines arbuscule development and functionality in the tomato arbuscular mycorrhiza. New Phytol. 175, 554-564. doi: 10.1111/j.1469-8137.2007. 02107.x

Hibbett, D. S., Binder, M., Bischoff, J. F., Blackwell, M., Cannon, P. F., Eriksson, O. E., et al. (2007). A higher-level phylogenetic classification of the Fungi. Mycol. Res. 111, 509-547. doi: 10.1016/j.mycres.2007.03.004

Hooker, W. J. (1981). Compendium of Potato Diseases. Saint Paul, MN: American Phytopathological Society.

Ijdo, M., Cranenbrouck, S., and Declerck, S. (2011). Methods for large-scale production of AM fungi: past, present, and future. Mycorrhiza 21, 1-16. doi: $10.1007 / \mathrm{s} 00572-010-0337-\mathrm{z}$

Javot, H., Pumplin, N., and Harrison, M. J. (2007). Phosphate in the arbuscular mycorrhizal symbiosis: transport properties and regulatory roles. Plant Cell Environ. 30, 310-322. doi: 10.1111/j.1365-3040.2006.01617.x

Jeffries, P., Gianinazzi, S., and Perotto, S. (2003). The contribution of arbuscular mycorrhizal fungi in sustainable maintenance of plant health and soil fertility. Biol. Fertil. Soils 37, 1-16.

Juge, C., Champagne, A., Coughlan, A. P., Juge, N., Parrott, L., and Piché, Y. (2009). Quantifying the growth of arbuscular mycorrhizal fungi: usefulness of the fractal dimension. Botany 87, 387-400. doi: 10.1139/B09-006

Juge, C., Samson, J., Bastien, C., Vierheilig, H., Coughlan, A., and Piché, Y. (2002). Breaking dormancy in spores of the arbuscular mycorrhizal fungus Glomus intraradices: a critical cold-storage period. Mycorrhiza 12, 37-42. doi: 10.1007/ s00572-001-0151-8 
Karandashov, V., Nagy, R., Wegmüller, S., Amrhein, N., and Bucher, M. (2004). Evolutionary conservation of a phosphate transporter in the arbuscular mycorrhizal symbiosis. Proc. Natl. Acad. Sci. U.S.A. 101, 6285-6290. doi: 10.1073/pnas.0306074101

Karimi, A., Khodaverdiloo, H., Sepehri, M., and Sadaghiani, M. R. (2011). Arbuscular mycorrhizal fungi and heavy metal contaminated soils. Afr. J. Microbiol. Res. 5, 1571-1576.

Kiiskinen, M., Korhonen, M., and Kangasja Ėrvi, J. (1997). Isolation and characterization of cDNA for a plant mitochondrial phosphate translocator (Mpt1). Ozone stress induces Mpt1 mRNA accumulation in birch (Betula pendula Roth). Plant Mol. Biol. 35, 271-279. doi: 10.1023/A:10058687 15571

Kobae, Y., and Hata, S. (2010). Dynamics of periarbuscular membranes visualized with a fluorescent phosphate transporter in arbuscular mycorrhizal roots of rice. Plant Cell Physiol. 51, 341-353. doi: 10.1093/pcp/pcq013

Kobae, Y., Tamura, Y., Takai, S., Banba, M., and Hata, S. (2010). Localized expression of arbuscular mycorrhiza-inducible ammonium transporters in soybean. Plant Cell Physiol. 51, 1411-1415. doi: 10.1093/pcp/ pcq099

Koide, R. T. (1985). The nature of growth depressions in sunflower caused by vesicular- arbuscular mycorrhizal infection. New Phytol. 99, 445-462. doi: 10.1111/j.1469-8137.1985.tb03672.x

Koske, R. E. (1981). Gigaspora gigantea: obervations on spore germination of a vesicular-arbuscular mycorrhizal fungus. Mycologia 730, 288-300. doi: 10.2307/ 3759650

Krajinski, F., Courty, P.-E., Sieh, D., Franken, P., Zhang, H., Bucher, M., et al. (2014). The H+-ATPase HAl of Medicago truncatula is essential for phosphate transport and plant growth during arbuscular mycorrhizal symbiosis. Plant Cell 26, 1808-1817. doi: 10.1105/tpc.113.120436

Lammers, P. J., Jun, J., Abubaker, J., Arreola, R., Gopalan, A., Bago, B., et al. (2001). The glyoxylate cycle in an arbuscular mycorrhizal fungus. Carbon flux and gene expression. Plant Physiol. 127, 1287-1298. doi: 10.1104/pp.010375

Leggewie, G., Willmitzer, L., and Riesmeier, J. W. (1997). Two cDNAs from potato are able to complement a phosphate uptake-deficient yeast mutant: identification of phosphate transporters from higher plants. Plant Cell 9, 381-392. doi: 10.1105/tpc.9.3.381

Linkies, A., and Leubner-Metzger, G. (2012). Beyond gibberellins and abscisic acid: how ethylene and jasmonates control seed germination. Plant Cell Rep. 31, 253-270. doi: 10.1007/s00299-011-1180-1

Liu, Z., Li, Y., Wang, J., He, X., and Tian, C. (2015). Different respiration metabolism between mycorrhizal and non-mycorrhizal rice under lowtemperature stress: a cry for help from the host. J. Agric. Sci. 153, 602-614. doi: 10.1017/S0021859614000434

Lynch, J. P. (2007). Roots of the second green revolution. Austr. J. Bot. 55, 493-512. doi: 10.1071/BT06118

Lynch, T., Erikson, B. J., and Finkelstein, R. R. (2012). Direct interactions of ABAinsensitive $(\mathrm{ABI})$ clade protein phosphatase (PP)2Cs with calcium-dependent protein kinases and ABA response element-binding bZIPs may contribute to turning off ABA response. Plant Mol. Biol. 80, 647-658. doi: 10.1007/s11103012-9973-3

Malusá, E., Sas-Paszt, L., and Ciesielska, J. (2012). Technologies for beneficial microorganisms inocula used as biofertilizers. Sci. World J. 2012:491206. doi: $10.1100 / 2012 / 491206$

Martin-Rodriguez, J., León-Morcillo, R., Vierheilig, H., Ocampo, J. A., LudwigMüller, J., and García-Garrido, J. M. (2011). Ethylene-dependent/ethylene independent $\mathrm{ABA}$ regulation of tomato plants colonized by arbuscular mycorrhiza fungi. New Phytol. 190, 193-205. doi: 10.1111/j.1469-8137.2010. 03610.x

Martin-Rodriguez, J. A., Leon-Morcillo, R., Vierheilig, H., Ocampo, J. A., LudwigMüller, J., and Garrido, J. M. (2010). Mycorrhization of the notabilis and sitiens tomato mutants in relation to abscisic acid and ethylene content. J. Plant Physiol. 167, 606-613. doi: 10.1016/j.jplph.2009.11.014

McArthur, D. A., and Knowles, N. R. (1992). Resistance responses of potato to vesicular-arbuscular mycorrhizal fungi under varying abiotic phosphorus levels. Plant Physiol. 100, 341-351. doi: 10.1104/pp.100.1.341

Medina, A., Jakobsen, I., Vassilev, N., Azcón, R., and Larsen, J. (2007). Fermentation of sugar beet waste by Aspergillus niger facilitates growth and $\mathrm{P}$ uptake of external mycelium of mixed populations of arbuscular mycorrhizal fungi. Soil Biol. Biochem. 39, 485-492. doi: 10.1016/j.soilbio.2006.08.019

Medina, A., Vassilev, N., and Azcón, R. (2010). The interactive effect of an $\mathrm{AM}$ fungus and an organic amendment with regard to improving inoculum potential and the growth and nutrition of Trifolium repens in Cd-contaminated soils. Appl. Soil Ecol. 44, 181-189. doi: 10.1016/j.apsoil.2009.12.004

Mercy, L., Svensson, J. T., Lucic, E., Cardoso, H. G., Nogales, A., Döring, M., et al. (2015). "AOX gene diversity in arbuscular mycorrhizal fungi (AMF) products a special challenge". Subchapter in Arnholdt-Schmit B. "From AOX diversity to functional marker development," in Alternative Respiratory Pathways in Higher Plants, eds K. J. Gupta, L. A. J. Mur, and B. Neelwarne (Oxford: John Wiley \& Sons, Inc.).

Millar, A. H., Whelan, J., Soole, K. L., and Day, D. A. (2011). Organization and regulation of mitochondrial respiration in plants. Annu. Rev. Plant Biol. 62, 79-104. doi: 10.1146/annurev-arplant-042110-103857

Miller, S. P., and Bever, J. D. (1999). Distribution of arbuscular mycorrhizal fungi in stands of the wetland grass Panicum hemitomon along a wide hydrologic gradient. Oecologia 119, 586-592. doi: 10.1007/s004420050823

Miller, S. P., and Sharitz, R. R. (2000). Manipulation of flooding and arbuscular mycorrhiza formation influences growth and nutrition of two semiaquatic grass species. Func. Ecol. 14, 738-748. doi: 10.1046/j.1365-2435.2000.00481.x

Møller, I. M., Berczi, A., Van der Plas, L. H. W., and Lambers, H. (1988). Measurement of the activity and capacity of the alternative pathway in intact plant-tissues: identification of problems and possible solutions. Physiol. Plant. 72, 642-649. doi: 10.1111/j.1399-3054.1988.tb09176.x

Mosse, B. (1959). The regular germination of resting spores and some observations on the growth requirements of an Endogone sp causing vesicular-arbuscular mycorrhiza. Trans. Br. Mycorrhizal Soc. 42, 273-286. doi: 10.1016/S00071536(56)80033-8

Mukerji, K. G., Manoharachary, C., and Chamola, B. P. (2002). Techniques in Mycorrhizal Studies. London: Kluwer Academic Publishers, 559. doi: 10.1007/ 978-94-017-3209-3

Murashige, T., and Skoog, F. (1962). A revised medium for rapid growth and bioassays with tobacco tissue cultures. Physiol. Plant. 15, 473-497. doi: 10.1111/ j.1399-3054.1962.tb08052.x

Nagy, R., Drissner, D., Amrhein, N., Jakobsen, I., and Bucher, M. (2009). Mycorrhizal phosphate uptake pathway in tomato is phosphorus-repressible and transcriptionally regulated. New Phytol. 181, 950-959. doi: 10.1111/j.14698137.2008.02721.x

Nagy, R., Karandashov, V., Chague, V., Kalinkevich, K., Tamasloukht, M., Xu, G., et al. (2005). The characterization of novel mycorrhiza-specific phosphate transporters from Lycopersicon esculentum and Solanum tuberosum uncovers functional redundancy in symbiotic phosphate transport in solanaceous species. Plant J. 42, 236-250. doi: 10.1111/j.1365-313X.2005.02364.x

Nagy, R., Vasconcelos, M. J., Zhao, S., McElver, J., Bruce, W., Amrhein, N., et al. (2006). Differential regulation of five Pht1 phosphate transporters from maize (Zea mays L.). Plant Biol. 8, 186-197. doi: 10.1055/s-2005-873052

Nogales, A., Nobre, T., Valadas, V., Ragonezi, C., Döring, M., Polidoros, A., et al. (2016). Can functional hologenomics aid tackling current challenges in plant breeding? Br. Funct. Genomics 15, 288-297. doi: 10.1093/bfgp/elv030

Pfaffl, M. W. (2001). A new mathematical model for relative quantification in real-time RT-PCR. Nucleic Acids Res. 29, 2002-2007. doi: 10.1093/nar/29.9.e45

Pfaffl, M. W., Tichopad, A., Prgomet, C., and Neuvians, T. P. (2004). Determination of stable housekeeping genes, differentially regulated target genes and sample integrity: bestKeeper - Excel-based tool using pair-wise correlations. Biotechnol. Lett. 26, 509-515. doi: 10.1023/B:BILE.0000019559.84305.47

Pfanz, H., Vodnik, D., Wittmann, C., Aschan, G., and Raschi, A. (2004). "Plants and geothermal $\mathrm{CO} 2$ exhalations. Survival and adaptation to a high $\mathrm{CO} 2$ environment," in Progress in Botany 65, eds K. Esser, U. Lüttge, J. W. Kadereit, and W. Beyschlag (Berlin: Springer-Verlag), 499-538.

Pfeffer, P. E., Douds, D. D., Bécard, G., and Shachar-Hill, Y. (1999). Carbon uptake and the metabolism and transport of lipids in an arbuscular mycorrhiza. Plant Physiol. 120, 587-598. doi: 10.1104/pp.120.2.587

Pinson, B., Merle, M., Franconi, J.-M., and Daignan-Fornier, B. (2004). Low affinity orthophosphate carriers regulate $\mathrm{PHO}$ gene expression independently of internal orthophosphate concentration in Saccharomyces cerevisiae. J. Biol. Chem. 279, 35273-35280. doi: 10.1074/jbc.M405398200 
Plaxton, W., and Tran, H. (2011). Metabolic adaptations of phosphate-starved plants. Plant Physiol. 156, 1006-1015. doi: 10.1104/pp.111.175281

Plenchette, C., Fortin, J. A., and Furlan, V. (1983). Growth responses of several plant species to mycorrhizae in a soil of moderate P-fertility. II. Soil fumigation induced stunting of plants corrected by reinoculation of the wild endomycorrhiza flora. Plant Soil 70, 211-217. doi: 10.1007/BF02374781

Porras-Soriano, A., Soriano-Martín, M. L., Porras-Piedra, A., and Azcón, R. (2009). Arbuscular mycorrhizal fungi increased growth, nutrient uptake and tolerance to salinity in olive trees under nursery conditions. J. Plant Physiol. 166, 1350-1359. doi: 10.1016/j.jplph.2009.02.010

Pozo, M. J., Cordier, C., Dumas-Gaudot, E., Gianinazzi, S., Barea, J. M., and AzcónAguilar, C. (2002). Localized vs systemic effect of arbuscular mycorrhizal fungi on defence responses to Phytophthora infection in tomato plants. J. Exp. Bot. 53, 525-534. doi: 10.1093/jexbot/53.368.525

Pozo, M. J., Verhage, A., Garcia-Andrade, J., García, J. M., and Azcón-Aguilar, C. (2009). "Priming plant defence against pathogens by arbuscular mycorrhizal fungi," in Mycorrhizas - Functional Processes and Ecological Impact, Vol. 9, eds C. Azcón-Aguilar, J. M. Barea, S. Gianinazzi, and V. Gianinazzi-Pearson (Berlin: Springer), 123-136.

Quarles, W. (1999). Plant disease biocontrol and VAM fungi. IPM Pract. 21, 1-9. doi: 10.2174/1874120701509010301

Rausch, C., Daram, P., Brunner, S., Jansa, J., Laloi, M., Leggewie, G., et al. (2001). A phosphate transporter expressed in arbuscule-containing cells in potato. Nature 414, 462-466. doi: 10.1038/35106601

Requena, N. (2005). Measuring quality of service: phosphate "a la carte" by arbuscular mycorrhizal fungi. New Phytol. 168, 268-271. doi: 10.1111/j.14698137.2005.01563.x

Rillig, M. C., and Steinberg, P. D. (2002). Glomalin production by an arbuscular mycorrhizal fungus: a mechanism of habitat modification? Soil Biol. Biochem. 34, 1371-1374. doi: 10.1016/s0038-0717(02)00060-3

Rizzuto, R., Sandonà, D., Brini, M., Capaldi, R. A., and Bisson, R. (1991). The most conserved nuclear-encoded polypeptide of cytochrome c oxidase is the putative zinc-binding subunit: primary structure of subunit $\mathrm{V}$ from the slime mold Dictyostelium discoideum. Biochim. Biophys. Acta 1129, 100-104. doi: 10.1016/0167-4781(91)90220-G

Ronsheim, M. L. (2012). The effect of mycorrhizae on plant growth and reproduction varies with soil phosphorus and developmental stage. Am. Midl. Nat. 167, 28-39. doi: 10.1674/0003-0031-167.1.28

Rook, F., Hadingham, S. A., Li, Y., and Bevan, M. W. (2006). Sugar and ABA response pathways and the control of gene expression. Plant Cell Environ. 29, 426-434. doi: 10.1111/j.1365-3040.2005.01477.x

Ruiz, O. H., Gonzalez, A., Almeida, A. J., Tamayo, D., Garcia, A. M., Restrepo, A., et al. (2011). Alternative oxidase mediates pathogen resistance in Paracoccidioides brasiliensis infection. PLoS Negl. Trop. Dis. 5:e1353. doi: 10.1371/journal.pntd.0001353

Ruzicka, D. R., Hausmann, N. T., Barrios-Masias, F. H., Jackson, L. E., and Schachtman, D. P. (2012). Transcriptomic and metabolic responses of mycorrhizal roots to nitrogen patches under field conditions. Plant Soil 350, 145-162. doi: 10.1007/s11104-011-0890-z

Saif, S. R. (1981). The influence of soil aeration on the efficiency of vesiculararbuscular mycorrhizae. 1. Effect of soil oxygen on the growth and mineral uptake of Eupatorium odoratum L. inoculated with Glomus macrocarpus. New Phytol. 88, 649-659. doi: 10.1111/j.1469-8137.1981.tb01741.x

Saini, G. R. (1976). Relationship between potato yield and oxygen diffusion rate of subsoil. Agron. J. 68, 823-825. doi: 10.2134/agronj1976. $00021962006800050036 \mathrm{x}$

Sakano, K. (2001). Metabolic regulation of $\mathrm{pH}$ in plant cells: role of cytoplasmic $\mathrm{pH}$ in defense reaction and secondary metabolism. Int. Rev. Cytol. 206, 1-44. doi: 10.1016/S0074-7696(01)06018-1

Salcedo-Hernandez, R., Escamilla, E., and Ruiz-Herrera, J. (1994). Organization and regulation of the mitochondrial oxidative pathway in Mucor rouxii. Microbiology 140, 399-407. doi: 10.1099/13500872-140-2-399

Sanders, F. E. (1975). "The effect of foliar-applied phosphate on the mycorrhizal infection of onion roots," in Endomycorrhizas, eds F. E. Sanders, B. Mosse, and P. B. Tinker (London: Academic Press), 261-276.

Schreiner, R. P. (2010). Foliar sprays containing phosphorus (P) have minimal impact on 'Pinot noir' growth and P status, mycorrhizal colonization, and fruit quality. HortScience 45, 815-820.
Schreiner, R. P., and Linderman, R. G. (2005). Mycorrhizal colonization in dryland vineyards of the Willamette Valley, Oregon. Small Fruits Rev. 4, 41-55. doi: 10.1300/J301v04n03_04

Sengottaiyan, P., Ruiz-Pavon, L., and Persson, B. L. (2013). Functional expression, purification and reconstitution of the recombinant phosphate transporter Pho89 of Saccharomyces cerevisiae. FEBS J. 280, 965-975. doi: 10.1111/febs. 12090

Sesay, A., Stewart, C. R., and Shibles, R. M. (1986). Effects of KCN and salicylhydroxamic acid on respiration of soybean leaves at different ages. Plant Physiol. 82, 443-447. doi: 10.1104/pp.82.2.443

Sieger, S. M., Kristensen, B. K., Robson, C. A., Amirsadeghi, S., Eng, E. W. Y., Abdel-Mesih, A., et al. (2005). The role of alternative oxidase in modulating carbon use efficiency and growth during macronutrient stress in tobacco cells. J. Exp. Bot. 56, 1499-1515. doi: 10.1093/jxb/ eri146

Simons, B. H., Millenaar, F. F., Mulder, L., Van Loon, L. C., and Lambers, H. (1999). Enhanced expression and activation of the alternative oxidase during infection of Arabidopsis with Pseudomonas syringae pv tomato. Plant Physiol. 120, 529-538. doi: 10.1104/pp.120.2.529

Singh, S. (2001). Role of mycorrhiza in tree plantings in the field, Part II: field inoculation, fungal succession, and effect of climatic and edaphic factors. Mycorrhiza News 12, 2-12.

Siquiera, J. O., and Hubbell, D. H. (1986). Effect of organic substrates on germination and germ tube growth of vesicular-arbuscular mycorrhizal fungus spores in vitro. Pesqui. Agropecu. Bras. 21, 523-527.

Smith, F. A., Grace, E. J., and Smith, S. E. (2009). More than a carbon economy: nutrient trade and ecological sustainability in facultative arbuscular mycorrhizal symbioses. New Phytol. 182, 347-358. doi: 10.1111/j.1469-8137. 2008.02753.x

Smith, F. A., and Smith, S. E. (2011a). What is the significance of the arbuscular mycorrhizal colonization of many economically important crop plants? Plant Soil 348, 63-79. doi: 10.1007/s11104-011-0865-0

Smith, S. E., Jakobsen, I., Grønlund, M., and Smith, F. A. (2011). Roles of arbuscular mycorrhizas in plant phosphorus nutrition: interactions between pathways of phosphorus uptake in arbuscular mycorrhizal roots have important implications for understanding and manipulating plant phosphorus acquisition. Plant Physiol. 156, 1050-1057. doi: 10.1104/pp.111.174581

Smith, S. E., and Read, D. J. (2008). Mycorrhizal Symbiosis. Cambridge: Academic Press.

Smith, S. E., and Smith, F. A. (2011b). Roles of arbuscular mycorrhizas in plant nutrition and growth: new paradigms from cellular to ecosystem scales. Annu. Rev. Plant Biol. 62, 227-250. doi: 10.1146/annurev-arplant-042110-103846

Spreen Brouwer, K., van Valen, T., Day, D. A., and Lambers, H. (1986). Hydroxamate-stimulated O2 uptake in roots of Pisum sativum and Zea mays, mediated by a peroxidase. Plant Physiol. 82, 236-240. doi: 10.1104/pp.82. 1.236

St-Arnaud, M., Hamel, C., Vimard, B., Caron, M., and Fortin, J. A. (1996). Enhanced hyphal growth and spore production of the arbuscular mycorrhizal fungus Glomus intraradices in an in vitro system in absence of host roots. Mycol. Res. 100, 328-332. doi: 10.1016/S0953-7562(96)80164-X

Tamasloukht, M., Séjalon-Delmas, N., Kluever, A., Jauneau, A., Roux, C., Bécard, G., et al. (2003). Root factors induce mitochondrial related gene expression and fungal respiration during the developmental switch from asymbiosis to presymbiosis in the arbuscular mycorrhizal fungus Gigaspora rosea. Plant Physiol. 131, 1468-1478. doi: 10.1104/pp.012898

Tamura, K., Stecher, G., Peterson, D., Filipski, A., and Kumar, S. (2013). MEGA6: molecular evolutionary genetics analysis version 6.0. Mol Biol Evol. 30, 2725-2729. doi: 10.1093/molbev/mst197

Thomazella, D. P., Teixeira, P. J., Oliveira, H. C., Saviani, E. E., Rincones, J., Toni, I. M., et al. (2012). The hemibiotrophic cacao pathogen Moniliophthora perniciosa depends on a mitochondrial alternative oxidase for biotrophic development. New Phytol. 194, 1025-1034. doi: 10.1111/j.1469-8137.2012. 04119.x

Tisserant, E., Kohler, A., Dozolme-Seddas, P., Balestrini, R., Benabdellah, K., Colard, A., et al. (2012). The transcriptome of the arbuscular mycorrhizal fungus Glomus intraradices (DAOM197198) reveals functional tradeoffs in an obligate symbiont. New Phytol. 193, 755-769. doi: 10.1111/j.1469-8137.2011. 03948.x 
Tisserant, E., Malbreil, M., Kuo, A., Kohler, A., Symeonidi, A., Balestrini, R., et al. (2013). Genome of an arbuscular mycorrhizal fungus provides insight into the oldest plant symbiosis. Proc. Natl. Acad. Sci. U.S.A. 110, 20117-20122. doi: $10.1073 /$ pnas. 1313452110

Trépanier, M., Bécard, G., Moutoglis, P., Willemot, C., Gagné, S., Avis, T. J., et al. (2005). Dependence of arbuscular-mycorrhizal fungi on their plant host for palmitic acid synthesis. Appl. Environ. Microbiol. 71, 5341-5347. doi: 10.1128/ AEM.71.9.5341-5347.2005

Trouvelot, A., Kough, J. L., and Gianinazzi-Pearson, V. (1986). "Mesure du taux de mycorhization ayant une signification fonctionnelle," in Aspects Physiologiques et Génétiques des Mycorhizes, eds V. Gianinazzi-Pearson and S. Gianinazzi (Paris: INRA Press,), 217-222.

Umbach, A. L., Ng, V. S., and Siedow, J. N. (2006). Regulation of plant alternative oxidase activity: a tale of two cysteines. Biochim. Biophys. Acta 1757, 135-142. doi: 10.1016/j.bbabio.2005.12.005

Umbach, A. L., and Siedow, J. N. (2000). The cyanide-resistant alternative oxidases from the fungi Pichia stipitis and Neurospora crassa are monomeric and lack regulatory features of the plant enzyme. Arch. Biochem. Biophys. 378, 234-245. doi: 10.1006/abbi.2000.1834

Uribe, D., and Khachatourians, G. G. (2008). Identification and characterization of an alternative oxidase in the entomopathogenic fungus Metarhizium anisopliae. Can. J. Microbiol. 54, 119-127. doi: 10.1139/w07-127

Ury, H. K. (1976). A comparison of four procedures for multiple comparisons among means (pairwise contrasts) for arbitrary sample sizes. Technometrics 18, 89-97. doi: 10.2307/1267921

van Aarle, I., Cavagnaro, T. R., Smith, S. E., Smith, F. A., and Dickson, S. (2005). Metabolic activity of Glomus intraradices in Arum- and Paris-type arbuscular mycorrhizal colonization. New Phytol. 166, 611-618. doi: 10.1111/j.1469-8137. 2005.01340.x

van der Heijden, M. G. A., Martin, F. M., Selosse, M.-A., and Sanders, I. R. (2015). Mycorrhizal ecology and evolution: the past, the present, and the future. New Phytol. 205, 1406-1423. doi: 10.1111/nph.13288

Vandesompele, J., De Preter, K., Pattyn, F., Poppe, B., Van Roy, N., De Paepe, A., et al. (2002). Accurate normalization of real-time quantitative RT-PCR data by geometric averaging of multiple internal control genes. Genome Biol. 3, RESEARCH0034. doi: 10.1186/gb-2002-3-7research0034

Vanlerberghe, G. C. (2013). Alternative oxidase: a mitochondrial respiratory pathway to maintain metabolic and signaling homeostasis during abiotic and biotic stress in plants. Int. J. Mol. Sci. 14, 6805-6847. doi: 10.3390/ijms14 046805

Vierheilig, H., Coughlan, A. P., Wyss, U., and Piche, Y. (1998). Ink and vinegar, a simple staining technique for arbuscular-mycorrhizal fungi. Appl. Environ. Microbiol. 64, 5004-5007.

Volkmar, K. M., and Woodbury, W. (1989). Effects of soil temperature and depth on colonization and root and shoot growth of barley inoculated with vesiculararbuscular mycorrhizae indigenous to Canadian prairie soil. Can. J. Bot. 67, 1702-1707. doi: 10.1139/b89-215

Vosátka, M., Albrechtová, J., and Patten, R. (2008). “The international market development for mycorrhizal technology," in Mycorrhiza, ed. A. Varma (Berlin: Springer), 419-438.

Walder, F., Boller, T., Wiemken, A., and Courty, P. E. (2016). Regulation of plants' phosphate uptake in common mycorrhizal networks: role of intraradical fungal phosphate transporters. Plant Signal. Behav. 11:e1131372. doi: 10.1080/ 15592324.2015.1131372

Walder, F., Brulé, D., Koegel, S., Wiemken, A., Boller, T., and Courty, P. E. (2015). Plant phosphorus acquisition in a common mycorrhizal network: regulation of phosphate transporter genes of the Pht1 family in sorghum and flax. New Phytol. 205, 1632-1645. doi: 10.1111/nph.13292

Walley, F. L., and Germida, J. J. (1995). Estimating the viability of vesiculararbuscular mycorrhizae fungal spores using tetrazolium salts as vital stains. Mycologia 87, 273-279. doi: 10.2307/3760914
Wang, H., Huang, J., and Bi, Y. (2010). Induction of alternative respiratory pathway involves nitric oxide, hydrogen peroxide and ethylene under salt stress. Plant Signal. Behav. 5, 1636-1637. doi: 10.4161/psb.5.12.13775

Wang, Y., Tang, S., and Jin, H. (2015). Effect of glucose, root exudates and N forms in mycorrhizal symbiosis using Rhizophagus intraradices. J. Soil Sci. Plant Nutr. 15, 726-736. doi: 10.4067/s0718-95162015005000049

Welchen, E., Chan, R. L., and Gonzalez, D. H. (2002). Metabolic regulation of genes encoding cytochrome c and cytochrome c oxidase subunit Vb in Arabidopsis. Plant Cell Environ. 25, 1605-1615. doi: 10.1046/j.1365-3040.2002.00940.x

Welchen, E., Hildebrandt, T. M., Lewejohann, D., Gonzalez, D. H., and Braun, H.P. (2012). Lack of cytochrome $\mathrm{c}$ in Arabidopsis decreases stability of Complex IV and modifies redox metabolism without affecting Complexes I and III. Biochim. Biophys. Acta 1817, 990-1001. doi: 10.1016/j.bbabio.2012.04.008

Wewer, V., Brands, M., and Dörmann, P. (2014). Fatty acid synthesis and lipid metabolism in the obligate biotrophic fungus Rhizophagus irregularis during mycorrhization of Lotus japonicus. Plant J. 79, 398-412. doi: 10.1111/tpj.12566

Whipps, J. M. (2004). Prospects and limitations for mycorrhizas in biocontrol of root pathogens. Can. J. Bot. 82, 1198-1227. doi: 10.1139/b04-082

White, C. N., and Rivin, C. J. (2000). Gibberellins and seed development in maize. II. Gibberellin synthesis inhibition enhances abscisic acid signaling in cultured embryos. Plant Physiol. 122, 1089-1098. doi: 10.1104/pp.122.4.1089

Wind, J. J., Peviani, A., Snel, B., Hanson, J., and Smeekens, S. C. (2012). ABI4: versatile activator and repressor. Trends Plant Sci. 19, 1360-1385.

Xu, F., Yuan, S., Zhang, D. W., Lv, X., and Lin, H. H. (2012). The role of alternative oxidase in tomato fruit ripening and its regulatory interaction with ethylene. J. Exp. Bot. 63, 5705-5716. doi: 10.1093/jxb/ers226

Xu, T., Yao, F., Liang, W. S., Li, Y. H., Li, D. R., Wang, H., et al. (2012). Involvement of alternative oxidase in the regulation of growth, development, and resistance to oxidative stress of Sclerotinia sclerotiorum. J. Microbiol. 50, 594-602. doi: 10.1007/s12275-012-2015-7

Yang, S.-Y., Grønlund, M., Jakobsen, I., Grotemeyer, M. S., Rentsch, D., Miyao, A., et al. (2012). Nonredundant regulation of rice arbuscular mycorrhizal symbiosis by two members of the PHOSPHATE TRANSPORTER1 gene family. Plant Cell 24, 4236-4251. doi: 10.1105/tpc.112.104901

Zhu, X. C., Song, F. B., Liu, S. Q., and Liu, T. D. (2011). Effects of arbuscular mycorrhizal fungus on photosynthesis and water status of maize under high temperature stress. Plant Soil 346, 189-199. doi: 10.1007/s11104-011-0809-8

Zhu, X. C., Song, F. B., and Xu, W. (2010). Arbuscular mycorrhizae improves low temperature stress in maize via alterations in host water status and photosynthesis. Plant Soil 331, 129-137. doi: 10.4161/psb.11498

Zsigmond, L., Rigó, G., Szarka, A., Székely, G., Ötvös, K., Darula, Z., et al. (2008). Arabidopsis PPR40 connects abiotic stress responses to mitochondrial electron transport. Plant Physiol. 149, 1721-1737. doi: 10.1104/pp.107.111260

Zsögön, A., Lambais, M. R., Benedito, V. A., Figueira, A. V. O., and Peres, L. E. P. (2008). Reduced arbuscular mycorrhizal colonization in tomato ethylene mutants. Sci. Agric. 65, 259-267. doi: 10.1590/S0103-90162008000300006

Conflict of Interest Statement: The authors declare that the research was conducted in the absence of any commercial or financial relationships that could be construed as a potential conflict of interest.

The reviewer AS and handling Editor declared their shared affiliation, and the handling Editor states that the process nevertheless met the standards of a fair and objective review.

Copyright (C) 2017 Mercy, Lucic-Mercy, Nogales, Poghosyan, Schneider and Arnholdt-Schmitt. This is an open-access article distributed under the terms of the Creative Commons Attribution License (CC BY). The use, distribution or reproduction in other forums is permitted, provided the original author(s) or licensor are credited and that the original publication in this journal is cited, in accordance with accepted academic practice. No use, distribution or reproduction is permitted which does not comply with these terms. 